UNIVERSIDADE DE SÃO PAULO

FACULDADE DE MEDICINA DE RIBEIRÃO PRETO

ALINE LAVADO TOLARDO

Pesquisa de compostos com potencial ação antiviral para os vírus Mayaro e Oropouche 
UNIVERSIDADE DE SÃO PAULO

FACULDADE DE MEDICINA DE RIBEIRÃO PRETO

ALINE LAVADO TOLARDO

\title{
Pesquisa de compostos com potencial ação antiviral para os vírus Mayaro e Oropouche
}

\author{
Tese apresentada ao Programa de Pós-graduação \\ em Clínica Médica da Universidade de São Paulo \\ para obtenção do Título de Doutor em Ciências
}

Ribeirão Preto 
AUTORIZO A REPRODUÇÃO E DIVULGAÇÃO TOTAL OU PARCIAL DESTE TRABALHO, POR QUALQUER MEIO CONVENCIONAL OU ELETRÔNICO, PARA FINS DE ESTUDO DE PESQUISA, DESDE QUE CITADA A FONTE.

\section{Catalogação na Publicação}

Serviço de Documentação

Faculdade de Medicina de Ribeirão Preto da Universidade de São Paulo

Tolardo, Aline Lavado

Pesquisa de compostos com potencial ação antiviral para os vírus

Mayaro e Oropouche / Aline Lavado Tolardo; Orientador: Prof. Dr.

Luiz Tadeu Moraes Figueiredo - Ribeirão Preto, 2019.

$61 p$ : il.; $30 \mathrm{~cm}$

Tese de Doutorado apresentada à Faculdade de Medicina de Ribeirão Preto da Universidade de São Paulo. Programa de Pós-Graduação em Clínica Médica - Investigação Biomédica, 2019.

1.Alphavirus 2. Antivirais 3.Orthobunyavirus 


\section{FOLHA DE APROVAÇÃO}

Nome: Aline Lavado Tolardo

Título: Pesquisa de compostos com potencial ação antiviral para os vírus Mayaro e Oropouche

Tese de Doutorado apresentada à Faculdade de Medicina de Ribeirão Preto da Universidade de São Paulo. Programa de Pós-Graduação em Clínica Médica - Investigação Biomédica.

Apresentada em

\section{Banca Examinadora}

Prof (a). Dr (a)

Instituição:

Julgamento

Prof (a). Dr (a)

Instituição:

Julgamento

Prof (a). Dr (a)

Instituição:

Julgamento 
Dedico este trabalho aos meus pais, meu irmão e ao Rodrigo, meus companheiros de vida e razão do meu esforço e dedicação. 


\section{AGRADECIMENTOS}

Agradeço ao Prof. Dr. Luiz Tadeu, meu orientador e professor por, primeiramente, ter me aceito como sua aluna, por sua orientação, todos os ensinamentos e pela dedicação a este trabalho e aos 8 anos que pude fazer parte de seu grupo de pesquisa. Agradeço também pelos momentos de descontração, cultura e boas histórias no laboratório. Minha eterna admiração.

A Professora Colleen Jonsson, da Universidade do Tennessee, minha segunda orientadora neste trabalho, por sua orientação, amizade e por todo o conhecimento que me foi passado durante e após o período que pude fazer parte de seu laboratório.

A todos os funcionários e docentes do Departamento de Clínica Médica, do Centro de Pesquisa em Virologia e de outros departamentos nos quais cursei minhas disciplinas, obrigada pela assistência e pelo conhecimento transmitido. Em especial, Adriana, Danillo, Dona Sueli, Dona Leila e Emerson.

Aos membros da banca examinadora, por fazerem parte do julgamento deste trabalho.

Ao Prof. Dr. Cláudio Costa Neto por ter disponibilizado a utilização de equipamentos de seu laboratório. Sem essa colaboração não seria possível a leitura de todas as placas que deram origem a este trabalho.

A todos os amigos do Centro de Pesquisa em Virologia, obrigada pelos bons momentos que passamos juntos, pelos cafés que compartilhamos, pelas risadas e pela acolhida nesses anos de trabalho.

Aos queridos colegas de laboratório, em especial Marília - que caminhou comigo durante esses 8 anos pelo mestrado e pelo doutorado - Bia, Victória, Dan, Léo, Angélica e Marcílio, por fazerem também um pouco parte desta tese. Obrigada pela amizade e pela acolhida nesses anos juntos. 
À Soraya e Pitty, obrigada pelo carinho, alegrias e por serem essas pessoas incríveis e por sempre estarem ao meu lado nesses anos, vocês moram no meu coração.

A minha querida amiga Denise, que não apenas me ajudou nos primeiros passos da pesquisa de antivirais, mas também se tornou uma grande amiga que levo pela vida.

Aos meus pais e meu irmão, por todo o amor, carinho e educação que me deram ao longo da vida. Vocês são a parte mais importante da minha vida, meu eterno amor e gratidão.

Aos meus sogros, Yara e Silvio, à Dona Aparecida, Juju e Fê, obrigada por serem minha família em São Paulo.

Aos meus dois grandes amores, Tapi e Chu, minhas companheiras do dia-a-dia, obrigada por serem o amor, afeto e carinho que eu precisava enquanto escrevia essa tese.

Ao Rodrigo, meu companheiro de vida, por ser meu maior e melhor incentivador em tudo que faço, obrigada por ser abraço sempre que precisei.

Aos amigos que Ribeirão me deu, que deixaram Ribeirão e que carrego pela vida, Luiza e Hudson, minha gratidão e amizade pelos momentos que passamos juntos, pela amizade e por sempre estarem presentes - mesmo na distância.

A Cícera e Nico, meus queridos amigos que Memphis me deu, obrigada por serem a família que tive no meu tempo fora do Brasil.

Aos amigos de longa data, que não deixaram a distância se fazer presente e sempre estiveram comigo, de perto ou de longe, obrigada pela amizade, pelo amor e pelo apoio.

À Fundação de Apoio à Pesquisa do Estado de São Paulo pelas duas bolsas e o financiamento deste estudo. 
"Science and everyday life cannot and should not be separated"

Rosalind Franklin 
TOLARDO, A.L. Pesquisa de compostos com potencial ação antiviral para os vírus Mayaro e Oropouche. 2019-61f. Tese (Doutorado) Faculdade de Medicina de Ribeirão Preto, Universidade de São Paulo, Ribeirão Preto.

\section{RESUMO}

Os Alphavirus e Orthobunyavirus são arbovírus importantes que causam grande impacto econômico e social no Brasil. Não existem antivirais disponíveis para o tratamento desses vírus. Portanto, é fundamental ter medicamentos terapêuticos que combatam os sintomas e sinais manifestados pela doença em casos leves e moderados. Neste trabalho, desenvolvemos um ensaio de luminescência baseada em células para a triagem de potenciais pequenas moléculas para os vírus Mayaro e Oropouche que mede o efeito citopático (CPE) induzido pelo vírus em células Vero usando o sistema CellTiter Glo baseado em luminescência. O ensaio foi validado no formato de placa de 384 poços e mostrou valores de $\mathrm{Z}$ maiores que 0,7, background maior que 30 e sinal-ruído maior que 10, demonstrando alta capacidade. Quatro bibliotecas de compostos foram testadas na concentração de $10 \mathrm{uM}$ para ambos os testes. Identificamos cinco compostos que inibiram o efeito citopático induzido pelos vírus em > 50\%, com valores de EC50/CC50 comparáveis aos determinados por outros ensaios baseados em células, validando assim a precisão e a capacidade do ensaio de servir como uma ferramenta para a descoberta de novos antivirais para os vírus Mayaro e Oropouche.

Palavras Chaves: Antivirais, Mayaro, Oropouche, arbovírus. 
TOLARDO, A.L. Research on compounds with potential antiviral action for Mayaro and Oropouche viruses. 2019-61f. Tese (Doutorado) Faculdade de Medicina de Ribeirão Preto, Universidade de São Paulo, Ribeirão Preto.

\begin{abstract}
Alphavirus and Orthobunyavirus are important arboviruses that have a major economic and social impact in Brazil. There are no antivirals available to treat these viruses. Therefore, it is essential to have therapeutic drugs that combat the symptoms and signs manifested by the disease in mild and moderate cases. In this thesis, we developed a cell-based luminescence assay for the screening of potential small molecules for Mayaro and Oropouche viruses that measures the virus-induced cytopathic effect (CPE) in Vero cells (ATCC CCL81) using the luminescence-based CellTiter Glo system. The assay was validated in a 384-well plate format and showed $\mathrm{Z}$ values greater than 0.7 , background greater than 30 and signal-to-noise greater than 10, demonstrating high capacity. Four compound libraries were tested at a concentration of $10 \mu \mathrm{M}$ for both tests. We identified five compounds that inhibited virus-induced cytopathic effect by $>50 \%$, with EC50/CC50 values comparable to those determined by other cell-based assays, thus validating the assay's accuracy and ability to serve as a tool for discovery of new antivirals for Mayaro and Oropouche viruses.
\end{abstract}

Key-words: Antivirals, Mayaro, Oropouche, arbovirus. 


\section{LISTA DE FIGURAS}

Figura 1. Ciclo dos arbovirus. Adaptado de Weaver, 2004 17

Figura 2. Organização do genoma e replicação dos Alphavirus 20

Figura 3. Genoma e estrutura do vírus Oropouche. Adaptado de Sakkas et al, 2018.... 24

Figura 4. Modelos de estudos de Drug Discovery. 28

Figura 5. Ensaios de plaque e títulos virais para Mayaro e Oropouche 39

Figura 6. Melhor densidade celular para Mayaro. 40

Figura 7. Melhor MOI para o vírus Mayaro com base na\% de viabilidade celular e no coeficiente de variação. MOI de 2,5 foi escolhido. 41

Figura 8. Melhor MOI para o vírus Oropouche com base na\% de viabilidade celular e no coeficiente de variação. MOI de 1.0 foi escolhido

Figura 9. Distribuição gráfica de uma placa Z para o vírus Mayaro

Figurav10. Distribuição gráfica de uma placa Z para o vírus Oropouche 44

Figura 11. Curva de dose-resposta da Purdue Library com os hits encontrados para o vírus Mayaro 45

Figura 12. Curvas de dose-resposta para os hits da Purdue Library para o vírus Oropouche 45

Figura 13. Ensaio de redução de plaque para o virus Mayaro 46

Figura 14. Ensaio de redução de plaque para o vírus Oropouche 46

Figura 15. Ensaio de Tempo de adição para MAYV e OROV 47 


\section{LISTA DE TABELAS}

Tabela 1. Conclusões de parâmetros do desenvolvimento do ensaio para o vírus Mayaro.

Tabela 2. Conclusões de parâmetros do desenvolvimento do ensaio para o vírus Oropouche.

Tabela 3. Comparação dos valores de EC50, CC50 e índice de seletividade de cada composto selecionado 


\section{LISTA DE ABREVIAÇÕES}

ATCC - American Type Culture Collection

cDNA - DNA complementar

CHIKV - Vírus Chikungunya

CMC - Carboximetilcelulose

CPE - Efeito citopático

CPV - Centro de Pesquisa em Virologia

CTG - CellTiter Glo

DAA - direct-acting antivirals

DENV-1 - Vírus do Dengue sorotipo 1

DENV-2 - Vírus do Dengue sorotipo 2

DENV-3 - Vírus do Dengue sorotipo 3

DENV-4 - Vírus do Dengue sorotipo 4

DMSO - Dimetilsulfóxido

DNA - Ácido Desoxirribonucléico

E1 - Proteína estrutural 1

E1, E2, E3 - Proteínas Estruturais 1, 2 e 3

EEEV-Vírus da Encefalite Equina do Leste

FAPESP- Fundação de Amparo à Pesquisa do Estado de São Paulo

FDA - Agência federal de drogas nos Estados Unidos

FMRP- Faculdade de Medicina de Ribeirão Preto

HTS - High Throughput Screening

MAYV - Vírus Mayaro

MEM - Meio mínimo essencial

MLPCN - Molecular Libraries Probe Production Center Network

MOI - Multiplicity of infection

MUCV - Vírus Mucambo

NS1 - Proteína não estrutural 1

NS1, 2a, 2b, 3, 4a, 4b e 5 - Proteínas não estruturais 1, 2a, 2b, 3, 4a, 4b e 5

NsP1 - Proteína não estrutural 1

NsP1, 2 e 3 - Proteínas ou genes não estruturais 1,2 e 3

$\mathrm{ORF}$ - Open reading frame

OROV - Vírus Oropouche 
PBS - Tampão fosfato salino (phosphate buffered saline)

PCR - Reação em cadeia da Polimerase

RNA - Ácido Ribonucléico

RRV - Vírus Ross River

RT- Transcrição Reversa

RT-PCR - Reação em cadeia da Polimerase precedida de Transcrição Reversa

SFB - Soro Fetal Bovino

SFV - Vírus Semlik Forest

SI - Indíce de seletividade

SINV - Vírus Sindbis

SP- Estado de São Paulo

USP - Universidade de São Paulo

VEEV - Vírus da Encefalite Equina Venezuelana

WEEV - Vírus da Encefalite Equina do Oeste

YFV 17D - Vírus da Febre Amarela cepa17D

ZIKV - Vírus ZIka 


\section{Sumário}

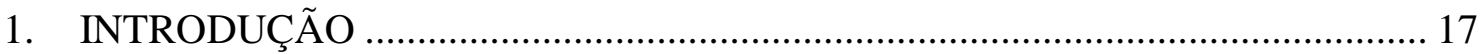

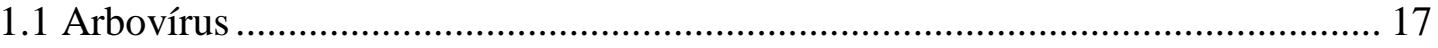

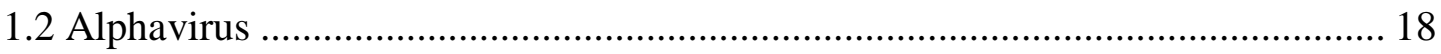

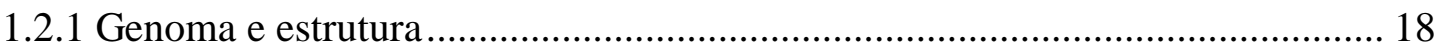

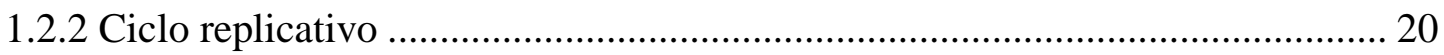

1.2.3 Manifestações clínicas e patogênese ........................................................... 21

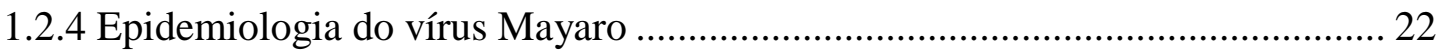

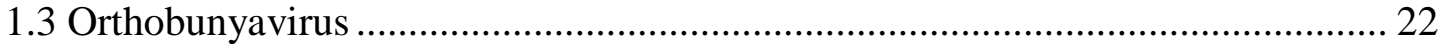

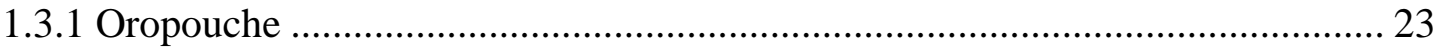

1.3.2 Genoma, estrutura e replicação de Orthobunyavirus......................................... 24

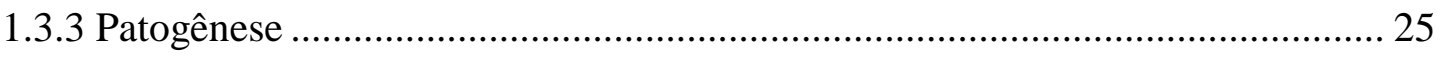

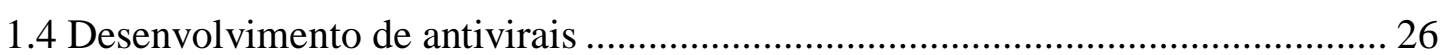

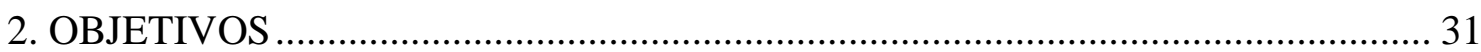

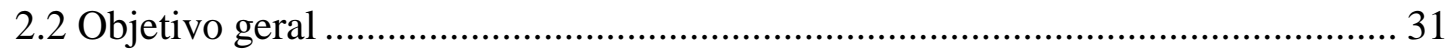

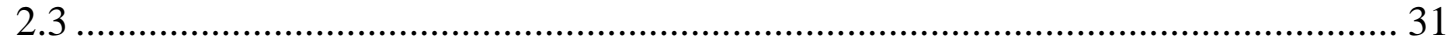

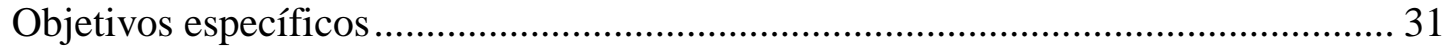

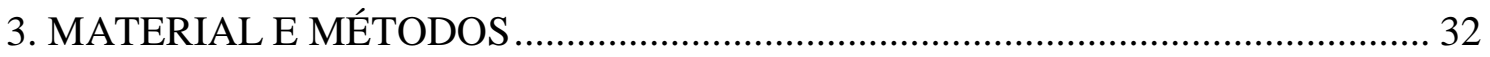

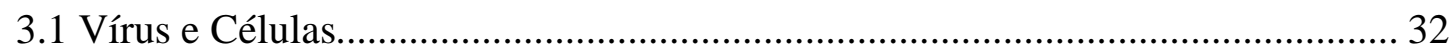

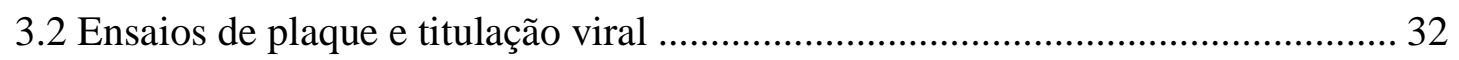

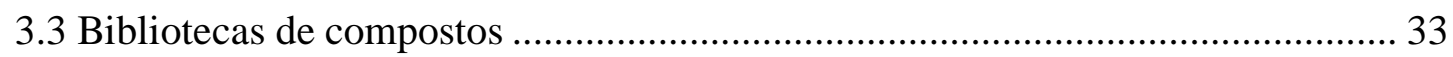

3.4 Padronização e otimização do ensaio HTS (High-throughput Screening) para

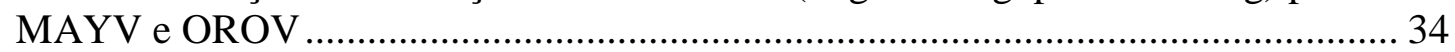

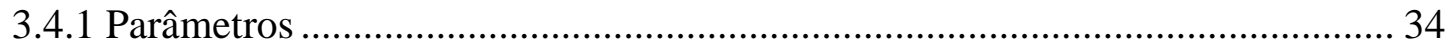

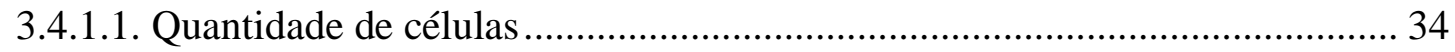

3.4.1.2 Multiplicidade de vírus ............................................................................... 34

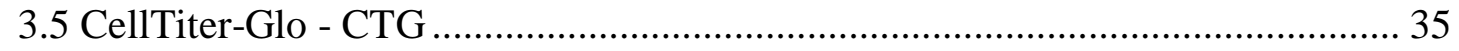

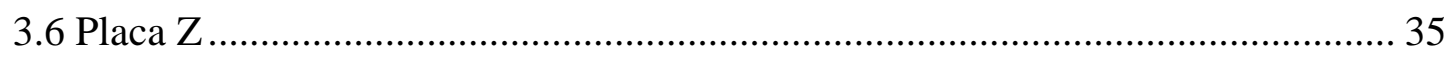

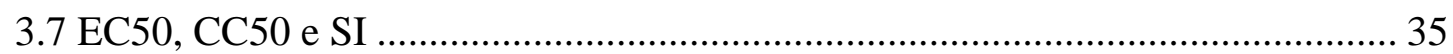

3.8 Ensaios de dose-resposta e citotoxicidade antiviral ........................................... 36

3.9 Ensaio de Validação com compostos de referência.............................................. 36

3.10 Ensaio de redução de plaque viral .................................................................... 37

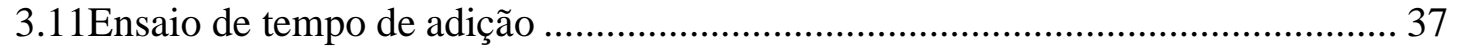

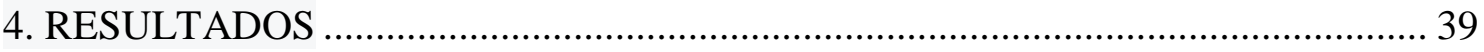

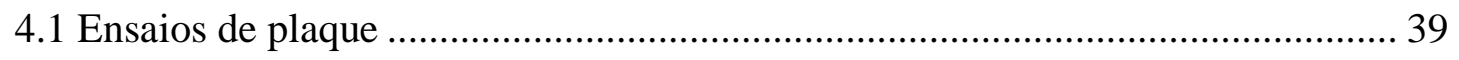

4.2 Desenvolvimento e padronização das etapas necessárias para o desenvolvimento do ensaio de HTS para Mayaro e Oropouche ............................................................. 39 
4.2.1 Número de células e concentração de DMSO ................................................... 40

4.2.2 Multiplicidade de infecção (MOI) ............................................................... 40

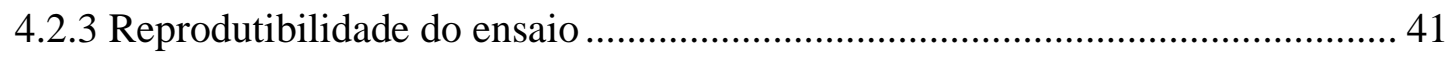

4.3 Triagem das Bibliotecas e validação dos ensaios ............................................... 43

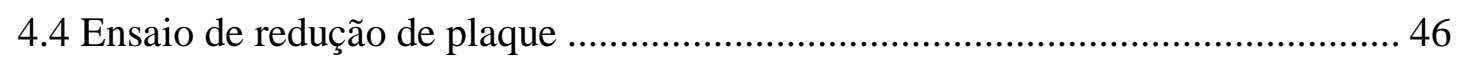

4.5 Ensaio de tempo de adição de droga para Mayaro e Oropouche ........................... 47

4.6 Ensaio de espectro de ação de antivirais para os compostos ................................ 48

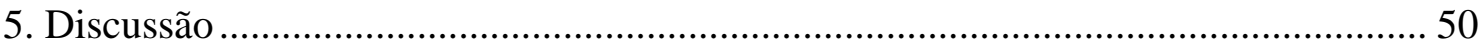

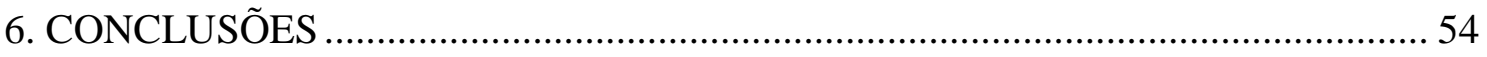

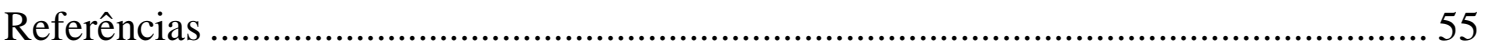




\section{INTRODUÇÃO}

\subsection{Arbovírus}

O Brasil é um país continental, com diferentes condições ambientais e que possui enorme variedade de flora, fauna e nos seus múltiplos nichos ecológicos são mantidas muitas zoonoses. Portanto, aqui existem amplas oportunidades de investigação básica e clínica a respeito de agentes causadores de doença humana, animal ou vegetal (IVERSSON, 1989). As arboviroses (viroses transmitidas por artrópodos) podem produzir epidemias, epizootias ou casos esporádicos e o quadro clínico de arboviroses pode variar de formas brandas com natureza febril, até formas graves, caracterizadas por manifestações hemorrágicas ou alterações neurológicas (PINHEIRO et al., 1991; FIGUEIREDO et al., 2002).

Fatores como, o crescimento populacional, a devastação de áreas silvestres, os transportes rápidos entre regiões distantes, entre outros, fizeram com que diversas arboviroses, anteriormente desconhecidas, aumentassem suas incidências nas últimas duas décadas, e até mesmo, algumas delas se tornaram sérios problemas de saúde pública (FIGUEIREDO, 2007; VASCONCELOS et al., 1998). Entre os arbovírus, denominação eminentemente epidemiológica, encontram-se vírus pertencentes à diferentes famílias, Rhabdoviridae, Flaviviridae, Togaviridae, Bunyaviridae, Reoviridae e Asfarviridae, responsáveis por doenças humanas e veterinárias (MURPHY, 1999; FIGUEIREDO, 2007).

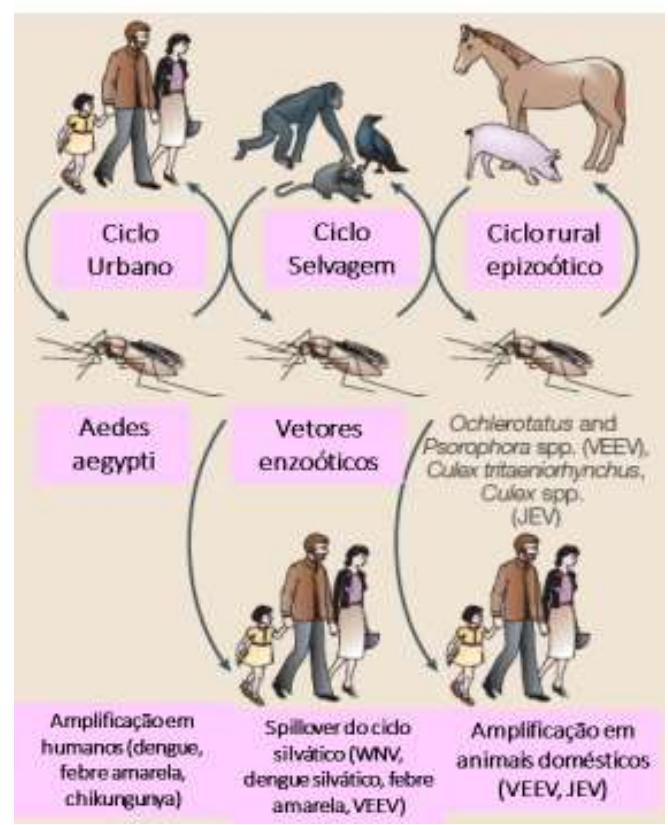

Figura 1. Ciclo dos arbovirus. Adaptado de Weaver, 2004. 
1.2 Alphavirus

Os Alphavirus são pequenos vírions esféricos e envelopados com genoma de RNA (Forrester, 2012). O gênero pertence à familia Togaviridae e inclui 32 espécies virais reconhecidas pelo International Committee on Taxonomy of Viruses (ICTV), sendo 31 delas pertencentes ao gênero Alphavirus (ICTV, 2011). Esses vírus ocorrem em todo o mundo, incluindo a Antártida e podem ser divididos naqueles do Novo Mundo e do Velho Mundo. A maioria destes Alphavirus podem causar encefalites ou doenças com acometimento articular. Na América do Sul, ocorre um Alphavirus que pode causar artralgias e até artrite. Trata-se do vírus Mayaro, que é transmitido, principalmente, por mosquitos Haemagogus. O vírus Mayaro vem produzindo no Brasil e países vizinhos diversos surtos de doença febril, como os 33 casos de febre do Mayaro descritos na cidade de Manaus em 2007 e 2008 (DE FIGUEIREDO et al., 2004; GRIFFIN, 2007; MOURAO et al., 2012).

\subsubsection{Genoma e estrutura}

Os arbovírus do gênero Alphavirus medem cerca de 70nm, são envelopados e possuem nucleocapsídeo de simetria icosaédrica. Internamente, o genoma viral é de RNA de fita simples com polaridade positiva, contendo aproximadamente 12.000 nucleotídeos dispostos em duas ORFs, a 5' e a 3', separadas por uma região não traduzida que faz a junção destas ORFs (KONONCHIK; HERNANDEZ; BROWN, 2011; UMMUL HANINAH et al., 2010). O genoma contém dois quadros abertos de leitura (Open Reading Frame - ORFs), o primeiro localizado à 5' do genoma, codifica as proteínas não estruturais e o segundo, localizado à 3' do genoma, em região controlada por um promotor subgenômico, codifica para as proteínas estruturais (STRAUSS, 1994). Ambos os quadros de leitura produzem polipeptídeos que são posteriormente clivados por proteases virais ou do próprio hospedeiro, originando quatro proteínas não estruturais (nsP1-4), envolvidas na patogênese e na 14 replicação do RNA viral e cinco proteínas estruturais (C, E3, E2, 6K, E1), requeridas para montagem e brotamento viral (HARDY, 1989).

As proteínas estruturais E1, E2, E3, C e 6K, são responsáveis pela formação das partículas virais. Estudos demonstraram que a proteína $\mathrm{C}$ é fundamental para a produção e viabilidade viral, enquanto que a função da proteína de envelope 3 (E3), não 
completamente elucidada, parece desempenhar funções diferentes em diversas espécies de alphavírus (OWEN, 1996). A proteína de envelope 1 (E1) é uma proteína de fusão à membrana celular do hospedeiro, contendo região peptídica de fusão altamente conservada e hidrofóbica (BOGGS, 1989). Outros estudos com SINV e RRV, demonstraram que a proteína de envelope 2 (E2), desempenha função de reconhecimento e ligação com receptor celular do hospedeiro, sendo diretamente relacionada ao tropismo viral (SMITH, 1995). A proteína 6K atua na montagem da partícula viral e funciona como canal iônico seletivo capaz de alterar a permeabilidade da membrana celular (IVANOVA, 1995).

Demostrou-se com SFV e SINV, que a proteína não estrutural 1 (nsP1) é necessária ao capeamento e metilação de novas fitas do RNA viral genômico e subgenômico. Também, estudos envolvendo transfecção da nsP1 em células HeLa, fizeram supor que durante a replicação viral a nsP1 ancora os complexos replicativos à membrana plasmática (AHOLA, 1997). Quanto à proteína não estrutural 2 (nsP2), sabe-se que em SFV e SINV, é necessária ao processamento do polipeptídeo das proteínas nãoestruturais (GOMEZ DE CEDRON, 1999). Estudos moleculares da nsP3, relacionam a mesma à modulação da patogenicidade viral (PARK, E. AND D.E. GRIFFIN, 2009; MALET, 2009). A proteína não estrutural 4 (nsP4) atua como RNA polimerase RNA-dependente (RdRP), responsável pela síntese das fitas de RNA da progênie viral (HAHN, Y.S et al., 1989). 
1.2.2 Ciclo replicativo

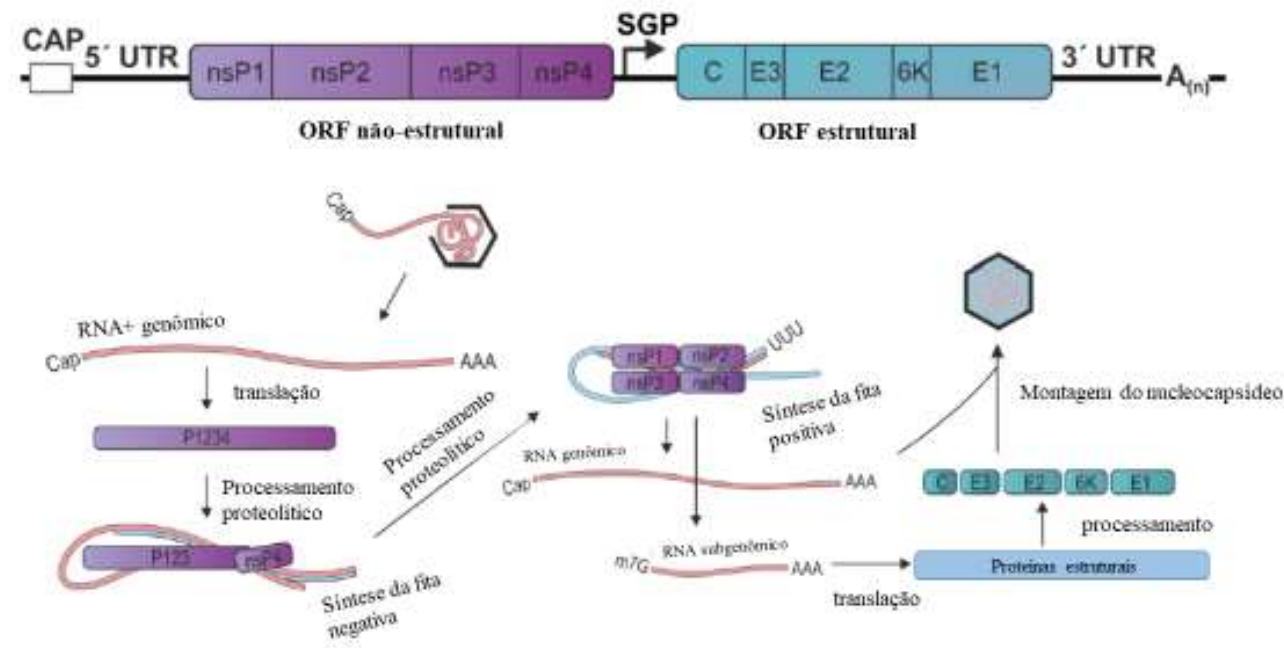

Figura 2. Organização do genoma e replicação dos Alphavirus. Adaptado de Pietila et al, 2017.

Os Alphavirus replicam em amplo número de células de seus hospedeiros, como, células neuronais, gliais, musculares lisas e estriadas, linfóides, sinoviais e do tecido adiposo marrom. Também, infectam um grande número de hospedeiros, sendo eles vertebrados (pássaros, mamíferos e répteis), ou invertebrados (mosquitos e outros artrópodes hematófagos) (CHAMBERLAIN, 1980; STRAUSS, 1994). O receptor específico de entrada celular dos alphavírus, foi identificado para SINV e trata-se da "proteína de macrófago associada-resistência natural' (nRAMP). A nRAMP é uma proteína celular amplamente conservada, de bactérias a seres humanos, envolvida no transporte de íons metálicos pela membrana plasmática (STILES, K.M. and M. KIELIAN, 2011).

Logo após a ligação ao receptor celular do hospedeiro pelo vírus, ocorre uma mudança conformacional nas glicoproteínas E2 e E1 seguida de endocitose da partícula viral em vesícula dependente de clatrinas formando um endossomo, que ao maturar, altera seu interior a um $\mathrm{pH}$ mais ácido (MEYER, W.J. and R.E. JOHNSTON, 1993). Essa acidificação desestabiliza os heterodímeros de E1-E2 e expõe o peptídeo de fusão da glicoproteína E1 à membrana celular. Dessa forma, o peptídeo de fusão é inserido na membrana endossomal formando poro por onde passa o nucleocapsídeo viral para atingir o citoplasma celular. Após a liberação do nucleocapsídeo o mesmo se dissocia liberando o genoma viral para tradução por vias ainda pouco elucidadas (HELENIUS, 1984). 
Os quadros de leitura do genoma viral são traduzidos para gerar os polipeptídeos estruturais e não estruturais. As proteínas não-estruturais são traduzidas diretamente a partir do genoma de RNA viral, que, para a maioria dos alphavírus geram duas poliproteínas, P123 e P1234. Estas são processadas exclusivamente por proteases virais localizadas na proteína nsP2 (STRAUSS, 1994). O polipeptídeo P123 parcialmente processado e a nsP4 formam complexo replicativo capaz de sintetizar uma fita intermediária de RNA(-) do genoma viral, que servirá de molde para síntese do RNA(+) genômico e para transcrição de $\mathrm{RNA}(+)$ da região subgenômica, que contém as proteínas estruturais virais [54]. Após processamento total das proteínas não estruturais em nsP1, Nsp2, nsP3 e nsP4, estas formam um complexo replicativo estável, capaz de sintetizar novas fitas de $\mathrm{RNA}(+)$ genômico viral, que são incorporadas à progênie (LEMM, J.A., et al., 1994).

Para formação das proteínas estruturais, forma-se um RNA(+), produzido a partir da fita de RNA(-) intermediária. Este RNA é produzido na região interna ribossomal (IRES) na fita de RNA(-) (STRAUSS, 1994). Após a tradução, o polipeptídeo sintetizado C-pE2-6K-E1 é processado para liberar a proteína de capsídeo (C) no citoplasma celular e o polipeptídeo resultante pE2-6K-E1, é transportado ao retículo endoplasmático e depois ao Complexo de Golgi, onde sofre modificações pós-traducionais antes de ser transportado para a membrana celularpara compor as proteínas de envelope viral durante o brotamento (GAROFF, H., M. SJOBERG, and R.H. CHENG, 2004)

\subsubsection{Manifestações clínicas e patogênese}

Através da picada por artrópodo hematófogo e inoculação subcutânea do alphavírus, a disseminação viral acontece por vasos linfáticos e sanguíneos. Assim como em outras infecções por arbovírus, a leucopenia é um achado comum durante a fase aguda da doença, e sugere que leucócitos possam ser sítios primários de replicação viral, assim como, o fígado e o baço (TESH, R.B., et al, 1990). Alphavirus, geralmente do novo mundo, acometem os ossos, músculos e tecidos articulares, ocasionando processos inflamatórios locais caracterizados por extenso infiltrado lifocitários, e também de células natural killers, neutrófilos e macrófagos (MORRISON, T.E., et al., 2011).

A maioria destes Alphavirus podem causar encefalites ou doenças com acometimento articular. Na América do Sul, ocorre um Alphavirus que pode causar artralgias e até artrite. Trata-se do vírus Mayaro, que é transmitido, principalmente, por mosquitos Haemagogus. O vírus Mayaro vem produzindo no Brasil e países vizinhos 
diversos surtos de doença febril, como os 33 casos de febre do Mayaro descritos na cidade de Manaus em 2007 e 2008 (DE FIGUEIREDO et al., 2004; GRIFFIN, 2007; MOURAO et al., 2012). As infecções por alphavírus podem variar de assintomáticas ou resultarem em doenças moderadas ou grave. A maior parte das infecções humanas são consideradas infecções finais, pois tais indivíduos não são capazes de transmitir o vírus a um novo hospedeiro (SCHWARTZ, 2010).

CHIKV e MAYV, alphavírus artritogênicos, podem causar uma doença aguda com aparecimento dos sintomas de 3 a 10 dias após a infecção, com viremia que pode perdurar de 4 a 7 dias. A doença inclui febre, cefaleia, petéquias, fadiga, artrite, artralgia e mialgia. A artrite é um sintoma comum nas infecções por estes vírus. A recuperação da dor e do inchaço articular ocorre após alguns dias, entretanto, vários relatos descrevem a persistência de dores nas articulações após meses ou anos. Também, a mialgia é um sintoma comum durante a infecção por alphavírus, resultado do tropismo viral por células musculares (DUPUIS-MAGUIRAGA, L., et al., 2012; TESH, 1999).

\subsubsection{Epidemiologia do vírus Mayaro}

O MAYV foi primeiramente isolado em 1954 em Trinidad e Tobago de amostras sanguíneas de cinco trabalhadores rurais com doença febril (ANDERSON, 1957). No Brasil, a maior parte dos casos de MAYV, foram descritos nas regiões Norte e CentroOeste, incluindo os estados do Pará, Amazonas, Mato Grosso e Goiás. Entretanto, os dados epidemiológicos ainda são limitados devido à ausência de testes sorológicos específicos, também, devido a sintomatologia das infecções por MAYV, que é similar a de outras infecções por arbovírus podendo ser subnotificada, tornando o MAYV uma arbovirose negligenciada no Brasil (WEAVER, 2010).

\subsection{Orthobunyavirus}

Os Orthobunyavirus, com 80 a 120 nm, posuem envelope glico-lipo-protéico. Internamente, possuem genoma de RNA fita simples e de polaridade negativa, trisegmentado. $\mathrm{O}$ segmento L codifica uma proteína grande que tem atividade de RNApolimerase-RNA-dependente e que faz a transcrição e a replicação do RNA genômico. M codifica uma poliproteína cuja clivagem origina as glicoproteínas de superfície Gc e Gn, além da proteína não estrutural NSm. S codifica a proteína do nucleocapsídeo $(\mathrm{N})$ e a proteína não estrutural NSs em ORFs superpostas (SCHMALJOHN, 2004). 


\subsubsection{Oropouche}

O vírus Oropouche (OROV) é um arbovírus da família Bunyaviridae, do gênero Orthobunyavirus. Trata-se de um dos principais arbovírus causadores de doença humana nas Américas do Sul, Central e já foi o segundo mais frequente arbovírus que ocorre no Brasil (PINHEIRO, 1981; LEDUC, 1989). O primeiro isolamento do vírus ocorreu em 1955, a partir do sangue de um paciente febril e de um lote de mosquitos Coquillettidia venezuelensis, em Vega do Oropouche, em Trinidad (ANDERSON, 1961). Reconhecido em 1960 no Brasil, os primeiros isolamentos foram obtidos do sangue de um bicho preguiça (Bradypus tridactylus) e de um lote de mosquitos Ochlerotatus serratus, no Estado do Pará (PINHEIRO, 1962). Desde então, dezenas de epidemias causadas por OROV já foram relatadas na Amazônia brasileira e na de outros países sul-americanos (PINHEIRO, 2004). OROV possui um ciclo urbano que tem seres humanos como hospedeiros e como vetor, o mosquito Culicoides paraensis (PINHEIRO, 2004). Além de produzir grande número de casos na Amazônia, o vírus Oropouche pode se adaptar a mosquitos antropofilicos, dispersando-se por todo o Brasil.

OROV é mantido em dois ciclos epidemiológicos, o urbano e o silvestre. O ciclo silvestre envolve diferentes hospedeiros vertebrados e vários possíveis vetores artrópodes (PINHEIRO; TRAVASSOS DA ROSA; VASCONCELOS, 2004), e o ciclo urbano ocorre em cidades tropicais, tendo seres humanos como principais hospedeiros e a mosca hematófaga Culicoides paraensis, popularmente conhecida como maruim, como principal vetor (PINHEIRO et al., 1981). Em áreas urbanas OROV é disseminado predominantemente em surtos epidêmicos de largas proporções que acometem especialmente populações ribeirinhas da região amazônica, mas também têm sido registrados casos esporádicos (MOURÃO et al., 2009).

Apesar da circulação do OROV no Brasil ser fortemente predominante na região norte, principalmente nos estados do Pará, Amazonas, Amapá, Acre, Rondônia, Tocantins e Maranhão (AZEVEDO et al., 2007), houve o relativamente recente isolamento do agente em um símio do gênero Callithrix spp encontrado morto no Parque Nacional Grande Sertão Veredas, no município de Arinos, MG (NUNES et al., 2005). O vírus isolado era do genótipo III, anteriormente registrado apenas no Panamá, o que evidencia o potencial de disseminação do vírus para outras regiões da América do Sul, com especial destaque a populosa região sudeste do Brasil (NUNES et al., 2005). Mais recentemente 
OROV foi detectado por RT-PCR e por imunofluorescência de leucócitos do sangue periférico, em uma paciente que adquiriu o vírus em viagem de férias a Porto Seguro, no sul da Bahia em 2014, podendo ser considerado o primeiro caso documentado de infecção humana por OROV adquirido fora da região amazônica (LUNA et al., 2017).

\subsubsection{Genoma, estrutura e replicação de Orthobunyavirus}

Tem se tornado progressivamente mais claro que existem significantes diferenças de estrutura e mecanismos moleculares entre diferentes Orthobunyavirus, e é provável que existam exceções às generalizações comumente feitas para o gênero (ELLIOTT, 2014). Como outros Orthobunyavirus, OROV possui diâmetro entre 80-120 nm, envelopado, com glicoproteínas de superfície inseridas na bicamada lipídica (Figura X). O genoma se constitui de três segmentos de RNA de polaridade negativa: L (large), M (medium) e S (small) (NICHOL et al., 2001; SCHMALJOHN; NICHOL, 2006; GUU; ZHENG; TAO, 2012, ELLIOTT; SCHMALJOHN, 2013).

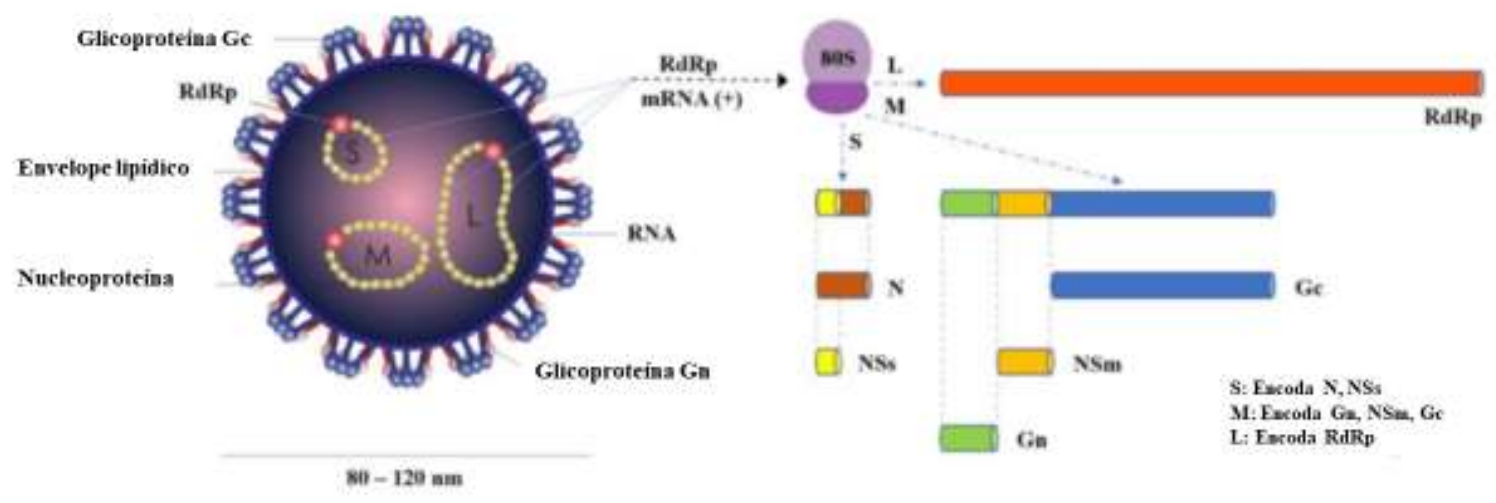

Figura 3. Genoma e estrutura do vírus Oropouche. Adaptado de Sakkas et al, 2018.

O segmento L de RNA codifica uma proteína grande (L), que tem atividade de RNApolimerase-RNA-dependente $(\mathrm{RpRd})$, que é parte integrante dos nucleocapsídeos, e executa a transcrição e a replicação dos segmentos do RNA genômico. O segmento $\mathrm{M}$ de RNA codifica uma poliproteína, cuja clivagem origina as glicoproteínas de superfície Gn e Gc, respectivamente das regiões 5' e 3' do mRNA, e a proteína não estrutural NSm, situada entre Gn e Gc. O segmento S de RNA codifica a proteína estrutural do nucleocapsídeo $\mathrm{N}$ e, em uma ORF (open reading frame) alternativa superposta, a proteína não estrutural NSs (ELLIOTT, 1990; SCHMALJOHN; NICHOL, 2006; ELLIOT, 2014). 
O ciclo de replicação dos Bunyaviridae se inicia com a ligação do vírus à célula hospedeira mediada pela interação das glicoproteínas virais com receptor cuja identidade ainda é desconhecida no caso do OROV. A entrada de OROV se dá por endocitose mediada por clatrina, cuja acidificação desencadeia o processo de fusão do envelope viral à membrana do endossomo levando ao desnudamento dos ribonucleocapsideos (SANTOS et al., 2008). A exposição ao citosol de ribonucleocapsídeos aos quais se associa a RpRd resulta na transcrição de mRNAs a partir do RNA genômico, cuja tradução dá origem às proteínas virais, bem como de RNA(+) complementar, de comprimento equivalente ao genoma, e que servirá de molde para a síntese dos genomas da progênie (SCHMALJOHN; NICHOL, 2006; ELLIOTT; SCHMALJOHN, 2013; ELLIOT, 2014).

Os vírus da família Bunyaviridae utilizam a estratégia de cap snatching, que consiste em remover estruturas cap 5' de mRNAs celulares e utilizá-los como iniciadores para a síntese de mRNAs virais, executada por uma atividade endonuclease da própria $\mathrm{RpRd}$ viral (GUU; ZHENG; TAO, 2012). À medida que há tradução de proteínas virais e produção de RNA genômico, ocorre a montagem de virions da progênie, com posterior maturação, que para a maioria dos Bunyaviridae já estudados ocorrem no complexo de Golgi (Figura 3, etapas 7, 8, 9 e 10), com exceção dos hantavírus Sin Nombre e Black Creek Canal, que brotam da membrana plasmática (SCHMALJOHN; NICHOL, 2006). A infecção de células HeLa com OROV BeAn19991 demonstrou que 30 a 36 horas após a infecção existe máxima produção de progênie, resultando em eficiência replicativa de cerca de $4 \log 10$ (ACRANI et al., 2010).

\subsubsection{Patogênese}

Muito pouco se sabe sobre a patogênese da infecção humana por OROV. Sabe-se que a infecção é sistêmica, com viremia nos primeiros 2-4 dias de sintomas (PINHEIRO et al., 1981), e que aproximadamente 5\% dos pacientes têm acometimento do sistema nervoso central (SNC), com meningite ou menigoencefalite (AZEVEDO et al., 2007; MOURÃO et al., 2009). O vírus é detectável no líquor (PINHEIRO et al., 1982; FIGUEIREDO, 2007), embora não se saiba como o vírus chega ao espaço subaracnóideo (PINHEIRO et al., 1982). O vírus infecta leucócitos do sangue periférico (LUNA et al., 2017), e é possível que atinja o SNC e outros tecidos pela estratégia de cavalo de Tróia, consequente à diapedese. A patogênese dos sintomas gerais e sistêmicos da infecção não 
é conhecida, mas à semelhança de outras infecções arbovirais poderia ser devida à reação inflamatória sistêmica da fase aguda com circulação de citocinas, e é possível que a ativação direta de leucócitos pela infecção por OROV contribua para esse quadro. É curioso que cerca de 2 a 10 dias após o fim dos sintomas cerca de metade dos pacientes com OROV sofrem recrudescência dos sintomas, com quadro idêntico ao da fase aguda, porém sem viremia detectável por isolamento em cultura de células (PINHEIRO et al., 1981; PINHEIRO; TRAVASSOS DA ROSA; VASCONCELOS, 2004). Mortes devidas a infecção por OROV nunca foram relatadas, e não existem dados de autopsia disponíveis.

\subsection{Desenvolvimento de antivirais}

Originalmente, pesquisas de compostos antivirais in vitro se limitavam a análise de extratos ou substâncias que inibiam a infecção viral em cultura celular e em modelos animais. Esta investigação detectava a ação antiviral sem saber qual das múltiplas substâncias contidas no vegetal tinham especificamente a ação antiviral. Isto demanda laboriosos processos de purificação e separação de componentes. Também, muitos compostos precisavam ser estruturalmente modificados para que produzissem antivirais potentes. Este processo evoluiu de várias formas, entre elas, os screenings de pequenas moléculas. Estudos recentes mostram a produção de sondas a partir de uma coleção de aproximadamente 500.000 pequenas moléculas contidas nos Molecular Libraries Probe Production Center Network (MLPCN), centros dentro de laboratórios de pesquisa espalhados pelos Estados Unidos, oriundos do Projeto Molecular Libraries Small Molecule Repository (MLSMR), do National Institute of Health (NIH) nos Estados Unidos, cujo objetivo consiste em identificar, adquirir, manter e distribuir estas moléculas. Essas pequenas moléculas, ou chamados compostos, são quimicamente diversas, possuem atividades biológicas conhecidas ou desconhecidas e são alvo de Highthroughput screenings (HTS) por um conjunto diversificado de ensaios biológicos, em diferentes centros de pesquisa, para a descoberta de antivirais. As estruturas químicas dos compostos, juntamente com os dados de triagem associados e obtidos a partir dos MLSCN, são compartilhados com o público através do PubChem, uma plataforma dentro do sistema NCBI do NIH.

Atualmente, seis categorias de ensaios podem ser utilizadas para a triagem de pequenas moléculas antivirais: os de viabilidade celular, os ensaios por ELISA, os 
métodos de detecção molecular, os que analisam células vivas por microscopia e ainda, técnicas clássicas, virológicas e bioquímicas.

Até o momento não existem medicamentos específicos para o tratamento de infecções causadas por praticamente nenhum arbovírus, e os esforços de saúde pública estão unidos em estratégias de prevenção, como o controle de vetores e administração de vacinas (POERSCH et al. 2005; KUMAR et al. 2010; HERMANN et al. 2015). Na ausência de tratamentos específicos, a única opção é o tratamento dos sintomas associados com o uso de analgésicos, antipiréticos e reposição de fluído corporal, o que não impede a transmissão do vírus para os mosquitos vetores (POERSCH et al. 2005; KUMAR et al. 2010; PASTORINO et al. 2010).

Nas últimas décadas, a indústria e a academia fizeram grandes esforços para descobrir e desenvolver novos antivirais, com maior ênfase para o vírus da Dengue, e mais recentemente para combater a infecção pelo ZIKV (SAIZ AND MARTÍNACEBES 2017; J. G. H. LOW, OOI, AND VASUDEVAN 2017).

A busca por antivirais tem sido realizada por meio de diferentes abordagens que incluem a triagem de bibliotecas de compostos e pelo reposicionamento de drogas clínicas utilizadas para outras doenças (SAIZ AND MARTÍN-ACEBES 2017; ABUSHOUK, NEGIDA, AND AHMED, 2016). Com isso, inúmeros compostos foram testados, como análogos/derivados de nucleosídeos, inibidores de polimerases e da síntese de nucleosídeos, imunomoduladores, antibióticos, antimaláricos, antihelmínticos, entre outros (SAIZ AND MARTÍN-ACEBES, 2017). Muitos compostos com atividade contra flavivírus já foram identificados a partir desses ensaios, e embora o alvo molecular (ou alvos) desses compostos ainda não tenham sido identificados, o espectro de atividade desses compostos poderia ser considerado como um ponto de partida para o desenvolvimento de antivirais (BOLDESCU et al., 2017).

O reposicionamento de drogas tem sido muito utilizado para avaliar a atividade de compostos comerciais para DENV. Os ensaios mais recentes utilizaram algumas drogas conhecidas, como cloroquina, prednisolona, balapiravir, celgosivir e lovastatina (J. G. H. LOW, OOI, AND VASUDEVAN, 2017). O balapiravir, é um pró-fármaco que foi originalmente desenvolvido para o tratamento de hepatite $\mathrm{C}$, e foi descrito como tendo atividade in vitro contra DENV; porém, ensaios clínicos de fase II com pacientes infectados com dengue não resultou na melhora do quadro clínico e viral dos pacientes (EK EYER et al., 2018; JULANDER, 2013). O celgosivir, que também é um pró-fármaco, já foi testado para HIV e HCV, exerce sua atividade antiviral pela inibição da enzima $\alpha$ 
-glicosidase I e II. Ensaios clínicos de fase 1 com pacientes infectados com DENV mostraram que celgosvir foi seguro e bem tolerado, porém não reduziu a carga viral e os sintomas clínicos dos pacientes infectados (J. G. LOW, et al. 2014).

Todas as outras drogas também foram consideradas seguras em pacientes com dengue aguda, mas nenhum conseguiu reduzir a viremia ou melhorar o quadro clínico dos pacientes (TRICOU et al. 2010; TAM et al. 2012; WHITEHORN, et al. 2016). Muitos dos compostos descobertos até o momento precisam ser aprimorados quanto as suas propriedades de ADME para dar continuidade no processo de desenvolvimento de drogas, mas não invalidam a sua contribuição para a elucidação de mecanismos da replicação viral. Muitas vezes esses compostos podem ser utilizados como sondas moleculares, e a susceptibilidade ou resistência a esses compostos poderia revelar se determinado alvo marcado é usado pelo vírus (ADCOCK et al., 2017; BOLDESCU, et al. 2017).

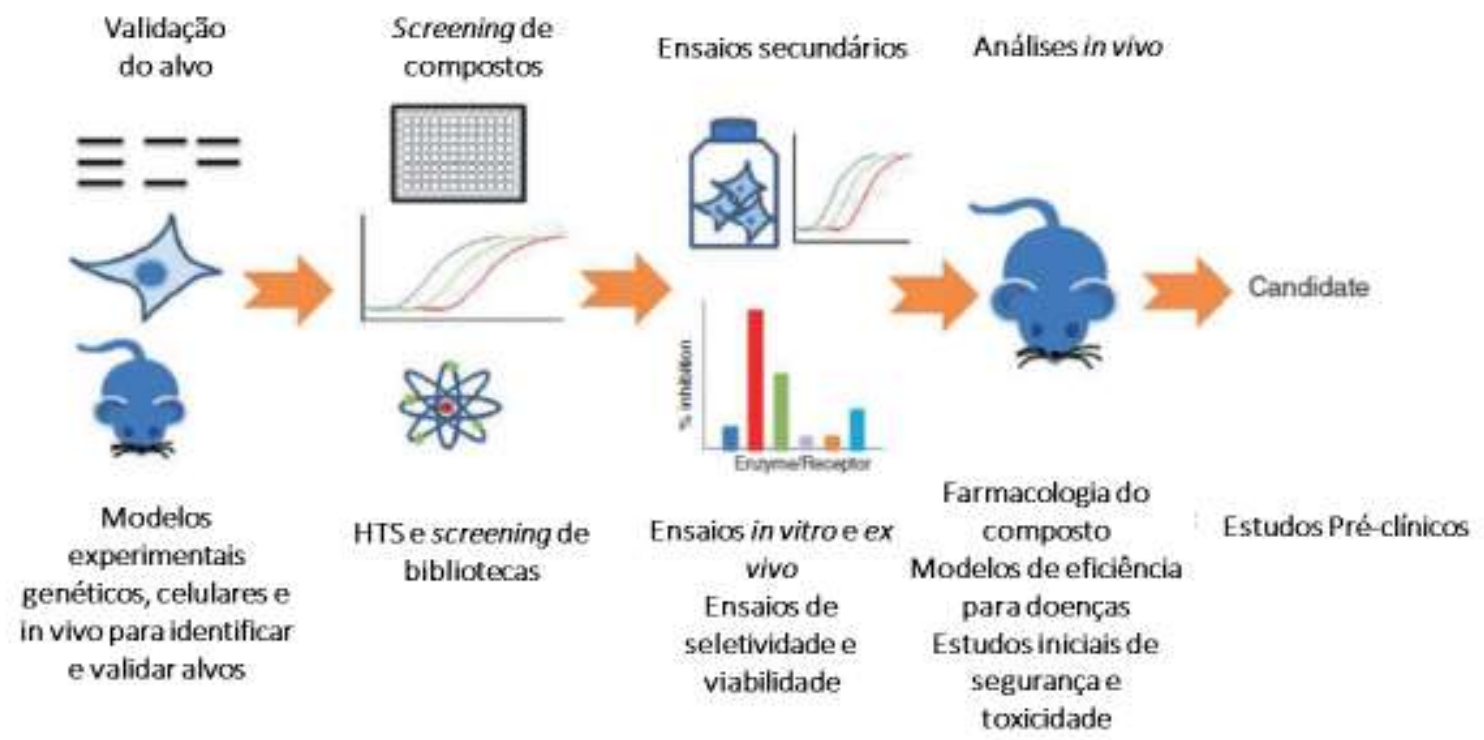

Figura 4. Modelos de estudos de Drug Discovery. Adaptado de Hugues et al.

Atualmente existem duas principais classes de antivirais: (i) antivirais de ação direta (direct-acting antivirals - DAAs), e (ii) antivirais de ação no hospedeiro (hosttargeting antivirals - HTAs) (CABARCAS-MONTALVO et al. 2016; MARTINEZ et al. 2015; BOLDESCU et al. 2017). A primeira classe engloba drogas que afetem diretamente os vírus, incluindo proteínas virais essenciais no processo de infecção ou o genoma do vírus (Martinez et al. 2015; Pastorino et al. 2010). Como os vírus possuem conjuntos específicos de genes, normalmente essa classe é composta por drogas muito seletivas para um certo tipo de vírus com pouca ou nenhuma seletividade contra outros 
genótipos do mesmo vírus, ou contra outros vírus. Um exemplo de DAA é o análogo de nucleotídeo GS-7977, comercialmente conhecido por sofosbuvir, que é um inibidor da NS5B de HCV (GANE et al. 2013). A fosforilação do GS-7977 pela célula hospedeira resulta na formação de um nucleosídeo ativo, que quando incorporado a cadeia de RNA em formação, promove a sua terminação (BOLDESCU et al. 2017; GANE et al. 2013). A segunda classe é formada por drogas que atuam sobre vias do hospedeiro envolvidas no ciclo de replicação do vírus, ou sobre a resposta imune do hospedeiro. Consequentemente, drogas dessa classe normalmente são de amplo espectro viral, atuando sobre diversos genótipos e múltiplos vírus (MARTINEZ et al. 2015; PASTORINO et al. 2010). Um exemplo de HTA é o Celgosivir que foi desenvolvida para o tratamento de $\mathrm{HCV}$. Celgosvir é um inibidor de $\alpha$-glucosidase, que é uma enzima da célula hospedeira responsável pela glicosilação das proteínas virais resultando no dobramento adequado das proteínas virais (J. G. LOW et al. 2018).

Algumas metodologias foram desenvolvidas para acelerar a avaliação da eficácia de antivirais, como: ensaios enzimáticos (HENDERSON, SAEEDI, AND KEENAN, 2012; C. C. YANG et al., 2011), ensaios in silico (Mirza et al. 2016; Nwaka and Ridley 2003) baseados nas estruturas de proteínas conhecidas (Noble et al. 2010), e ensaios baseados em células (ensaios fenotípicos) (HENDERSON, SAEEDI, AND KEENAN, 2012; LUCAS-HOURANI et al., 2013). Os ensaios enzimáticos/bioquímicos com alvo específicos normalmente utilizam proteínas virais estruturais e não-estruturais (Tam et al. 2012), consequentemente priorizando a classe dos DAAs. Esses ensaios são rápidos, relativamente fáceis, robustos, e contribuíram substancialmente para a descoberta de DAAs (BOLDESCU et al., 2017).

Os ensaios baseados em células podem ser classificados em três grupos principais: como a utilização de replicons subgenomicos, partículas semelhantes a vírus, contendo apenas proteínas estruturais do vírus ou vírus vivos (BOLDESCU et al., 2017). Os replicons subgenomicos geralmente são utilizados quando os compostos possuem alvo conhecido (BOLDESCU et al., 2017). As partículas semelhantes a vírus são interessantes para selecionar compostos capazes de inibir a infecção viral, mas não para o estudo da replicação ou disseminação viral, portanto esse sistema não imitam as características autenticas da infecção viral (PANCHAL et al., 2010). Os resultados obtidos por esses dois ensaios devem ser avaliados com cuidado para evitar falso positivo devido a toxicidade celular causada por compostos, ou então pela interferência na leitura da luciferase (BOLDESCU et al., 2017). Além disso, a atividade dos compostos encontrados 
precisa ser reavaliada e confirmada em ensaios compartículas virais infectivas (KOUZNETSOVA et al., 2014). Ensaios com partículas virais vivas tradicionalmente usam ensaios baseados no monitoramento da replicação viral.

O efeito de determinado composto é monitorado tanto pela observação visual da redução dos efeitos citopáticos (CPE) causados (LI et al., 2018; GREEN et al. 2008), quanto pela quantificação do RNA viral por RT-PCR em tempo real (QING, LIU, et al., 2010; TOWNER et al. 2007). Esses ensaios são muito trabalhosos e demorados, por isso não são utilizados para triar uma grande quantidade de compostos, mas sim para avaliar a atividade de candidatos que já foram identificados por outros ensaios (GREEN et al. 2008; PANCHAL et al. 2010).

As interações vírus hospedeiro são importantes para o desenvolvimento de fármacos pois além de avaliar a atividade antiviral de determinado composto, é capaz de fornecer informações sobre as alterações fenotípicas e toxicidade causadas nas células hospedeiras (PANCHAL et al. 2010). Avanços na microscopia óptica juntamente com o auxílio de softwares de processamento de imagens levaram ao desenvolvimento de ensaios de alto conteúdo, que permitem medir as múltiplas respostas celulares à infecção e ao uso dos compostos, sendo uma alternativa para a busca de novos antivirais (PANCHAL et al. 2010). 


\section{OBJETIVOS}

\subsection{Objetivo geral}

Este trabalho teve como objetivo o desenvolvimento, automação e execução de um ensaio de viabilidade celular de alto rendimento (HTS) para os vírus Mayaro e Oropouche, considerando a atividade de compostos provenientes de diferentes bibliotecas comerciais e não comerciais. A triagem de compostos visou a busca de potenciais candidatos com atividade antiviral.

\subsection{Objetivos específicos}

$\checkmark$ Padronizar e otimizar duas técnicas de High Throughput Screening (HTS) para os vírus Mayaro e Oropouche;

$\checkmark$ Automatizar os ensaios para Mayaro e Oropouche;

$\checkmark$ Identificar potenciais compostos existentes com ação, in vitro, contra os vírus Oropouche e Mayaro;

$\checkmark$ Avaliar a citotoxicidade e provável mecanismo de ação destes compostos; 


\section{MATERIAL E MÉTODOS}

Este projeto foi realizado, no Centro de Pesquisa em Virologia da Faculdade de Medicina de Ribeirão Preto (FMRP-USP), sob orientação do Prof. Dr. Luiz Tadeu Moraes Figueiredo, e também no laboratório do Prof. Dr. Cláudio Miguel Costa-Neto do departamento de Bioquímica da FMRP. Os resultados aqui apresentados também fazem parte de colaboração com a Profa. Dra. Colleen B Jonsson desenvolvidos durante período sanduíche na Universidade do Tennessee (Memphis, TN).

\subsection{Vírus e Células}

Linhagem celular Vero: Linhagem celular isolada de rins de macaco da espécie Cercopithecus aethiops. Estas células foram cultivadas em meio MEM com 100 unidades/mL de Penicilina e $100 \mu \mathrm{g} / \mathrm{mL}$ de Estreptomicina (Vitrocell) suplementado com $10 \%$ de soro fetal bovino, a $37^{\circ} \mathrm{C}$, em estufa a $5 \%$ de $\mathrm{CO} 2$. As células foram tripsinizadas (solução de tripsina 0,05\% - EDTA - Vitrocell) a cada 3-4 dias e semeadas na densidade de 5x105 células/mL, em 25 mL, no frasco de cultura T175 (TPP).

Vírus e infecção: Estoques virais foram produzidos em células Vero (ATCC CCL81). Monocamadas de células mantidas a $37^{\circ} \mathrm{C}$ em frascos de $175 \mathrm{~cm}^{2}$ foram infectados com $100 \mu 1$ de cada vírus: Mayaro (BeAr20290) e Oropouche (BeAn 19991). Os frascos com células infectadas foram mantidos em incubadora por 1 hora para adsorver o vírus e então foram adicionados os frascos. armazenado a $37^{\circ} \mathrm{C}$ e após 2 ou 4 dias, respectivamente para MAYV e OROV, aliquotou-se o sobrenadante.

\subsection{Ensaios de plaque e titulação viral}

As células Vero foram distribuídas em placas de 24 poços e incubadas durante 24 horas a $37^{\circ} \mathrm{C}$ numa atmosfera contendo $5 \%$ de $\mathrm{CO}_{2}$ para formação de monocamada de células. Para o ensaio de placa, adicionamos diluições decimais de $10^{1}$ a $10^{10}$ de todos os estoques virais individuais de Mayaro e Oropouche. As placas foram incubadas durante 1 hora numa incubadora a $37^{\circ} \mathrm{C}$, sob agitação moderada, para adsorção viral. Em seguida, uma solução a 3\% de carboximetilcelulose estéril (Sigma-Aldrich, EUA) com 2,5\% de soro bovino fetal, em MEM, foi adicionada aos orifícios de sobreposição de $1 \mathrm{ml}$. As placas foram observadas quanto ao aparecimento de plaques. Para sobrepor as plaques, a 
cobertura foi rejeitada, os poços foram lavados com PBS e as células foram fixadas com solução de formalina a $10 \%$ em PBS, incubando durante uma hora à temperatura ambiente. No final, as células foram coradas com Preto de Naftaleno (Sigma-Aldrich, EUA). Para o cálculo dos títulos de vírus, foram contados plaques individualizados e claramente visíveis. Com base no número de plaques em células inoculadas na diluição e no volume conhecido, determinamos o título viral em Unidades Formadoras de Plaque (PFU/ml) por $\mathrm{ml}$.

\subsection{Bibliotecas de compostos}

Foram utilizadas quatro bibliotecas de compostos na padronização e validação do ensaio:

- Purdue University: 20 compostos farmacologicamente ativos obtidos do Dr. Jo Davidson e Dr. Aaron da Purdue University. As estruturas e nomes dos compostos não puderam ser reveladas nesta tese pois os mesmos encontram-se em processo de obtenção de patentes.

- University of Wisconsin: 621 compostos obtidos da University of Wisconsin.

- Prestwick Library: Uma coleção exclusiva de 1280 pequenas moléculas sem patente, com 95\% de medicamentos aprovados (FDA, EMA e outras agências) com alta diversidade química e farmacológica.

- Pathogen Box: o Pathogen Box contém 400 moléculas diferentes, semelhantes a medicamentos, ativas contra doenças negligenciadas de interesse e está disponível gratuitamente. Os compostos da Pathogen Box são fornecidos em placas de 96 poços, contendo $10 \mu \mathrm{L}$ de uma solução $10 \mathrm{mM}$ de dimetilsulfóxido (DMSO) de cada composto. Mediante solicitação, pesquisadores de todo o mundo recebem uma caixa de moléculas de patógenos para ajudar a catalisar a descoberta de medicamentos para doenças negligenciadas. Em troca, os pesquisadores são solicitados a compartilhar quaisquer dados gerados no domínio público dentro de 2 anos, criando um fórum aberto e colaborativo para pesquisa de medicamentos para doenças negligenciadas. 
Todas as bibliotecas foram diluídas em DMSO a 100\% a uma concentração de 10 $\mathrm{mM}$ e depois foram plaqueadas utilizando o equipamento Janus (Perkin Elmer) em uma placa de polipropileno de 384 poços ( $5 \mathrm{uL} /$ poço).

3.4 Padronização e otimização do ensaio HTS (High-throughput Screening) para MAYV e OROV

O ensaio HTS foi realizado no laboratório BSL2 para o vírus Mayaro e BSL3 para o vírus Oropouche. Ambos os ensaios foram otimizados em células Vero (ATCC CCL81).

\subsubsection{Parâmetros}

3.4.1.1. Quantidade de células

1000, 2000, 3000, 4000 e 5000 células/poço foram adicionadas em placas de 384 poços para a padronização do número de células dos ensaios tanto para MAYV quanto OROV, num volume de 20Ul. As placas foram incubadas overnight em uma estufa de $\mathrm{CO}_{2}$. No dia seguinte, DMSO em diferentes concentrações entre $0-1 \%$ foi adicionado às placas em um volume de $5 \mu 1$. As microplacas foram então incubadas por 72 horas a $37^{\circ} \mathrm{C}$ e $5 \%$ de $\mathrm{CO}_{2}$ em atmosfera úmida.

\subsubsection{Multiplicidade de vírus}

Após a padronização do número de células e concentração de DMSO, foram testados diferentes MOIs para MAYV e OROV. Os MOIs testados variavam entre 0,05 e 5 para ambos os vírus. Para o ensaio, um número de células previamente padronizado para cada um dos testes era adicionado em um volume de 20uL/poço em placas de 384 poços. As placas foram incubadas overnight em uma estufa de $\mathrm{CO}_{2}$. No dia seguinte, DMSO em uma concentração de $0,2 \%$ foi adicionado às placas em um volume de $5 \mu 1$. Duas horas depois, diferentes MOIs para MAYV e para OROV foram adicionados às placas em um volume de $5 \mu \mathrm{L} /$ poço. Todos os poços de controle também possuíam $0,2 \%$ 
de DMSO na concentração final. As microplacas foram então incubadas por 72 horas a $37^{\circ} \mathrm{C}$ e $5 \%$ de $\mathrm{CO}_{2}$ em atmosfera úmida.

\subsection{CellTiter-Glo - CTG}

O CellTiter-Glo® Luminescent Cell Viability Assay é um método homogêneo de determinar o número de células viáveis em cultura com base na quantificação do ATP presente, um indicador de células metabolicamente ativas. O CellTiter-Glo® é projetado para uso com formatos de múltiplas cavidades, tornando-o ideal para ensaios automatizados de triagem de alto rendimento (HTS), proliferação celular e citotoxicidade. O procedimento de ensaio homogêneo envolve a adição do reagente único (CellTiterGlo® Reagent) diretamente às células cultivadas em meio suplementado com soro. Lavagem de células, remoção de passos médios e múltiplos de pipetagem não são necessários.

Para este ensaio, após adicionar células (incubadas overnight a $37^{\circ} \mathrm{C}$ e $5 \%$ de $\mathrm{CO}_{2}$ em atmosfera úmida), DMSO ou composto no dia seguinte e, após 2h, o vírus (MAYV ou OROV), as microplacas foram então incubadas por 72 horas a $37^{\circ} \mathrm{C}$ e $5 \%$ de $\mathrm{CO}_{2}$ em atmosfera úmida. Foram, então, adicionados $30 \mathrm{uL}$ de reagente $\mathrm{CTG}$ sempre ao final de cada ensaio seguido de incubação por 20 min em agitador orbital e leitura das placas em leitor de luminescência (EnVision / Perkin Elmer)

\subsection{Placa Z}

O fator Z', que é adimensional e determina a qualidade do ensaio, é determinado pelo grau de separação entre os controles positivo e negativo, que pode ser calculado por uma equação. Como controle positivo, teremos células não infectadas e células infectadas não tratadas de controle negativo. $O$ teste foi validado se apresentando $Z \geq 0,5$.

\subsection{EC50, CC50 e SI}

Além disso, as curvas dose-resposta foram analisadas quanto à sua eficácia e valores de EC50, CC50 e índice de seletividade (SI). A eficácia foi determinada pela atividade máxima do composto, portanto, quanto mais eficaz a amostra, mais próximo de $100 \%$ será a atividade normalizada. O valor de EC50 foi definido como a concentração da amostra correspondente a 50\% de atividade normalizada (ou redução de 50\% na taxa 
de infecção). A potência das amostras está relacionada ao seu valor EC50 - quanto mais potente for a amostra, menor será seu valor EC50. O valor de CC50 indica a concentração da amostra que reduz a taxa de células em 50\%. A razão celular foi definida como a razão entre o número total de células do poço e o número médio de células no controle negativo. O índice de seletividade (SI) é a razão dos valores de CC50 por EC50. Quando a taxa de células da amostra na curva dose-resposta não retorna ao valor de CC50, o SI é considerado maior ou igual à relação entre a concentração máxima testada e o valor de EC50. Quanto maior o SI do composto, melhor o composto.

\subsection{Ensaios de dose-resposta e citotoxicidade antiviral}

Compostos que mostraram ação antiviral confirmada por teste de screening foram submetidos a testes dose-resposta e citotoxicidade. Para medir a inibição dose-resposta da infecção e a citotoxicidade dos compostos, preparamos placas de 384 poços contendo células Vero em um volume de $20 \mu \mathrm{l}$ e utilizamos diferentes concentrações dos compostos. A viabilidade celular foi avaliada com o reagente CellTiter-Glo (Promega, EUA) após incubação de $72 \mathrm{~h}$. Os procedimentos detalhados para esses procedimentos $\begin{array}{lllll}\text { estão } & \text { descritos } & \text { em } & \text { PubChem } & \text { AID: }\end{array}$ (http://pubchem.ncbi.nlm.nih.gov/assay/assay.cgi?aid=588727\&loc=ea_ras).

\subsection{Ensaio de Validação com compostos de referência}

A validação do ensaio foi feita usando compostos de referência com atividade antiviral como, por exemplo, o Interferon $\alpha$ 2A (Sigma-Aldrich). O ensaio foi feito em triplicata com o composto de referência diluído em série na proporção de 1:1 em 14 pontos, e com concentração inicial de $50 \mathrm{ng} / \mathrm{mL}$ de Interferon $\alpha 2 \mathrm{~A}$. O composto de referência e os controles foram adicionados nas placas de 384 poços e em seguida adicionadas $2 \times 10^{3}$ células/poço de Vero infectadas com uma multiplicidade de infecção (MOI) de 1.5 do vírus Mayaro e 1.0 do vírus Oropouche. 
3.10 Ensaio de redução de plaque viral

Placas de doze poços contendo células Vero com um dia de idade $\left(2 \times 10^{5}\right.$ células $\left./ \mathrm{ml}\right)$ foram infectadas com 300 PFU de MAYV. Após a infecção, um overlay contendo CMC (4\% CMC, 1X MEM-E, 2\% FBS) com ou sem os compostos (concentração final de 5 $\mathrm{uM}$ ) foi adicionado e incubado por $48 \mathrm{~h}$.

As placas foram coradas com cristal violeta a $0,2 \%$ em paraformaldeído a $4 \%$ e em seguida o número de plaques foi contabilizado.

\subsection{Ensaio de tempo de adição}

As células Vero foram semeadas a uma concentração de $6,0 \times 10^{3}$ células/poço em uma placa de 96 poços (Falcon). Depois de 24 horas, as células foram infectadas com MAYV ou OROV. Após o período de adsorção de 1 hora, o meio foi removido, e as células foram lavadas com PBS 1X para remoção de partículas virais não adsorvidas, e meio fresco foi adicionado. Os compostos selecionados e DMSO foram adicionados antes da infecção viral $(-1 h)$, durante a infecção viral (0h) e após a infecção viral $(+1 \mathrm{~h},+2 \mathrm{~h}$, $+4 \mathrm{~h},+6 \mathrm{~h},+8 \mathrm{~h},+10 \mathrm{~h}$ e $+12 \mathrm{~h}$ ). Após $48 \mathrm{~h}$ de incubação, os sobrenadantes e o lizado das células dos poços foram coletados, e a porcentagem de inibição da replicação viral foi avaliada por porcentagem de viabilidade celular através de luminescência.

\subsection{Análise dos dados}

A partir dos dados da triagem primária, as amostras testadas foram avaliadas considerando dois parâmetros: atividade normalizada (\%) e taxa celular. Os dados foram processados e analisados, para então realizar a seleção dos compostos que apresentaram atividade, que foram denominados hits. Normalmente, são selecionados de 1-2\% dos compostos da biblioteca para dar continuidade à triagem confirmatória por curvas de dose-resposta. Assim os valores de atividade normalizada e toxicidade celular adotados para a seleção dos hits variam de acordo com o vírus utilizado. As curvas de DRC foram analisadas, utilizando o software licenciado Graphpad Prism, quanto à sua eficácia e aos valores de EC50, CC50 e Índice de seletividade (SI). A eficácia foi determinada pela atividade máxima apresentada pelo composto, assim, quanto mais eficaz for a amostra, mais próximo de $100 \%$ será o valor da atividade normalizada. O valor de EC50 foi definido como a concentração da amostra que correspondente a $50 \%$ de atividade 
normalizada (ou 50\% de redução da taxa de infecção). O perfil de potência das amostras está diretamente relacionado com o seu valor de EC50 - quanto mais potente for a amostra, menor será seu valor de EC50 -. O valor de CC50 indica a concentração da amostra que reduz a viabilidade celular em 50\%. A taxa celular foi definida como número total de células do poço tratado e a média de células no controle negativo. $O$ índice de seletividade (SI) é a razão entre os valores de CC50 pelo EC50. Quando a avaliação da taxa celular da amostra na curva dose-resposta não retorna um valor de CC50, o SI é considerado maior ou igual à razão entre a concentração máxima testada e o valor de EC50. Quanto maior o SI do composto, melhor o composto. 


\section{RESULTADOS}

\subsection{Ensaios de plaque}

Para o cálculo dos títulos virais foram contados plaques individualizados e claramente visíveis. Com base no número de plaques em células inoculadas na diluição e no volume conhecido, determinamos o título viral em Unidades Formadoras de Plaque (PFU/ml) (Figura 1).
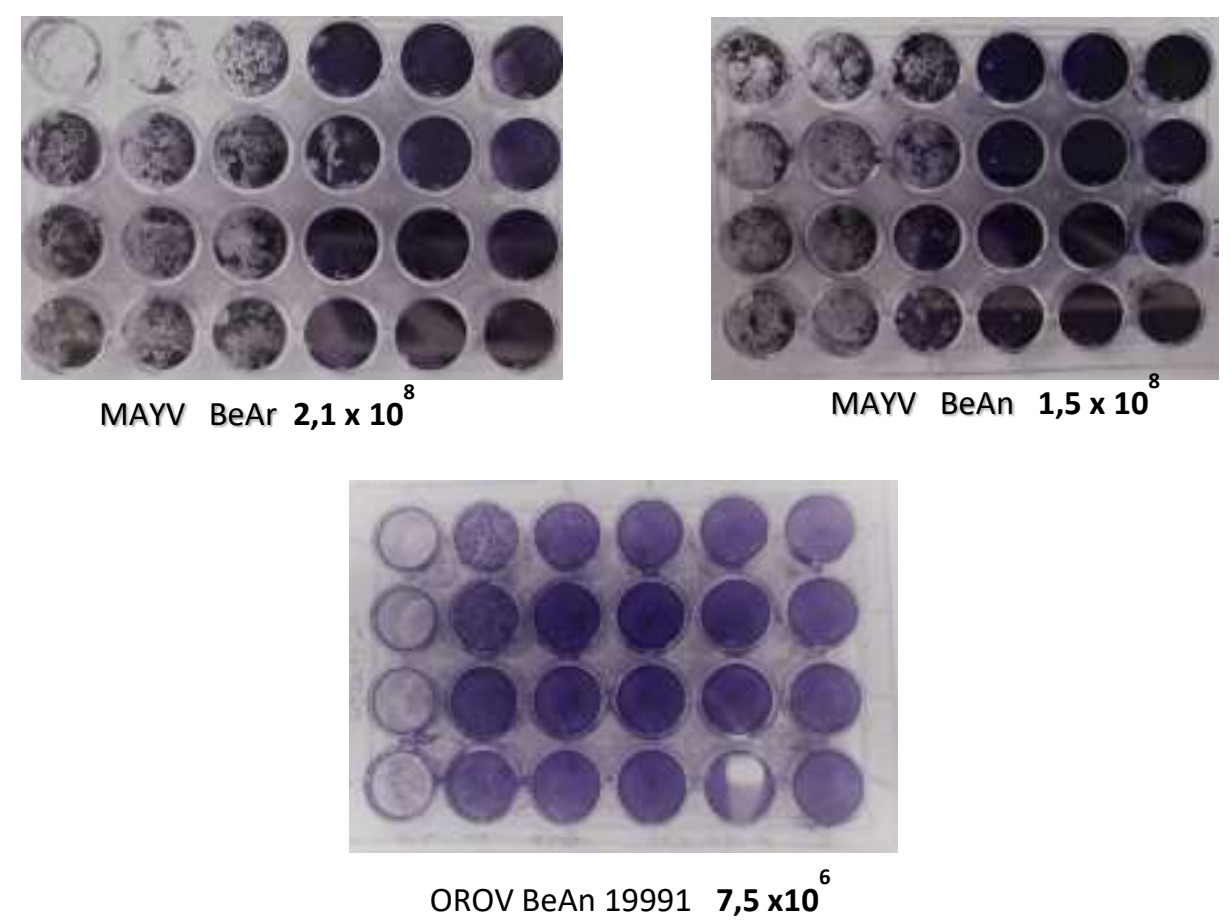

Figura 5. Ensaios de plaque e títulos virais para Mayaro e Oropouche

4.2 Desenvolvimento e padronização das etapas necessárias para o desenvolvimento do ensaio de HTS para Mayaro e Oropouche

O ensaio proposto de triagem de drogas contra MAYV e OROV visa identificar amostras com potencial atividade antiviral em um sistema que replica in vitro a infecção de células de mamíferos por vírus. Esses vírus podem infectar virtualmente qualquer tipo de linhagem celular, mas as células Vero foram escolhidas porque são células de crescimento aderentes em monocamada; são robustas, com volume do núcleo e 
citoplasma grande. Todos estes critérios facilitam a manipulação da célula e o desempenho do ensaio.

4.2.1 Número de células e concentração de DMSO

Foram testados números de células entre 1000 e 5000 células por poço tanto para o ensaio com MAYV quanto OROV. Os parâmetros avaliados na escolha do número de células para o ensaio levaram em consideração a porcentagem de viabilidade celular de acordo com a concentração de DMSO. As concentrações de DMSO utilizadas variando de 0 a $1 \%$ utilizando a leitura com o reagente CTG por luminescência usando o equipamento EnVision (PerkinElmer). Depois de avaliado, a melhor densidade celular por poço foi de 4500 para Oropouche e 5000 para Mayaro e a melhor concentração de DMSO foi de $0,2 \%$ (Figura 6).

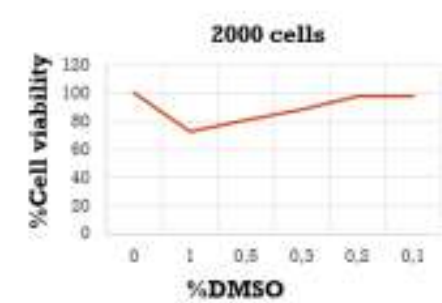

4000 cells

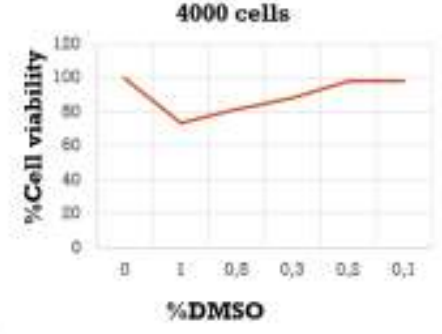

Figura 6. Melhor densidade celular para Mayaro
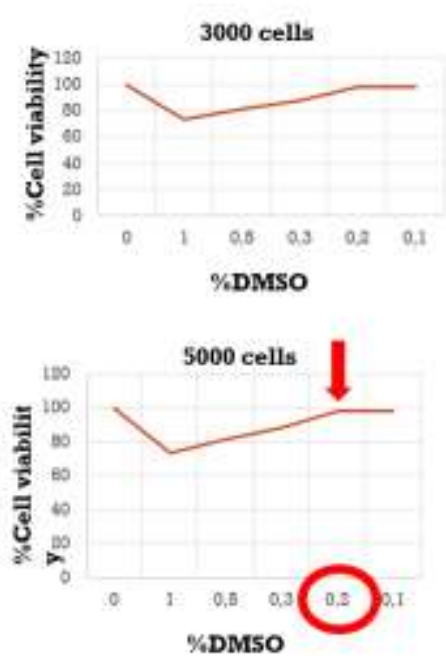

4.2.2 Multiplicidade de infecção (MOI)

A melhor multiplicidade de infecção (MOI) foi determinada para cada vírus (Figuras 7 e 8). A seleção do MOI mais adequado levou em conta a porcentagem de viabilidade celular de acordo com o Coeficiente de Variação (CV) em comparação com 
o controle não infectado, utilizando a leitura com o reagente CTG por luminescência usando o equipamento EnVision (PerkinElmer). O melhor MOI para o vírus Mayaro foi o de 2,5 e para o vírus Oropouche foi de 1,0.

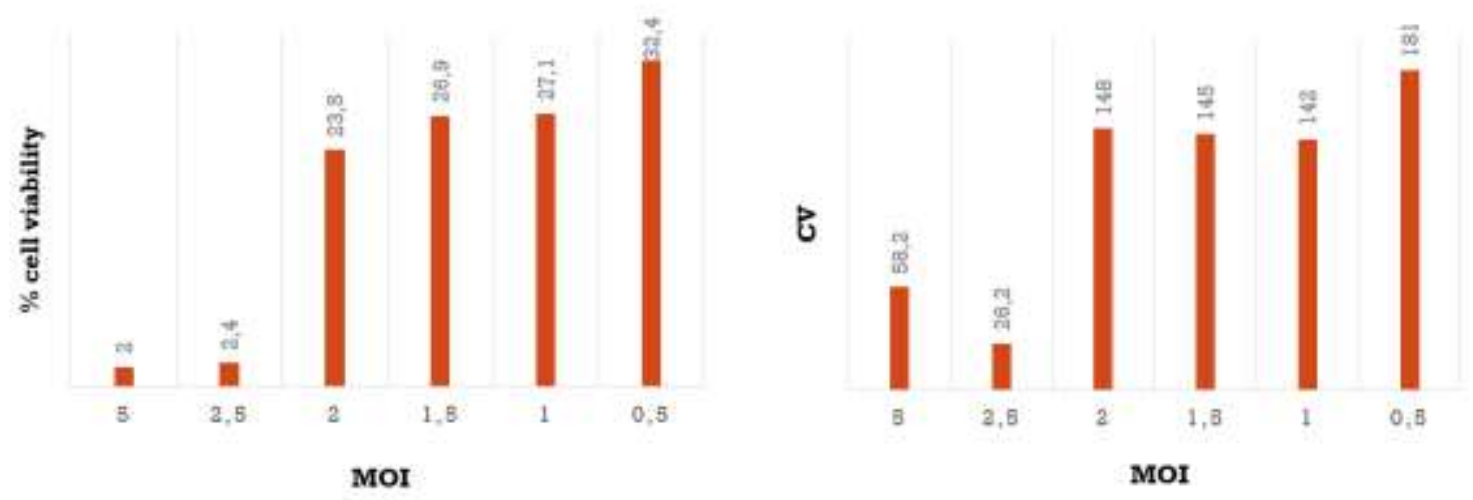

Figura 7. Melhor MOI para o vírus Mayaro com base na\% de viabilidade celular e no coeficiente de variação. MOI de 2,5 foi escolhido.

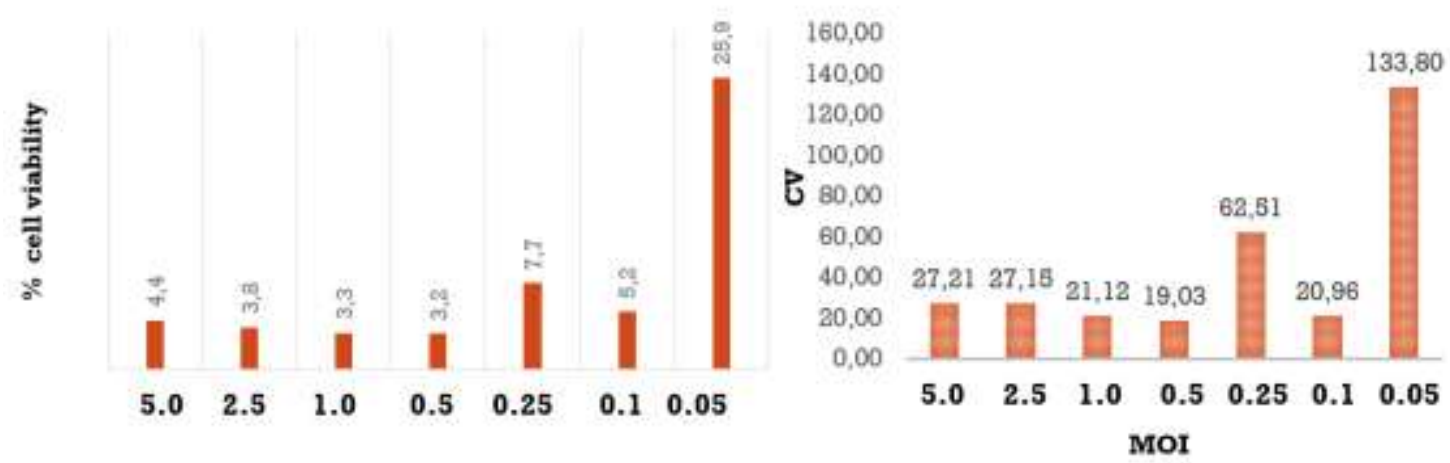

Figura 8. Melhor MOI para o vírus Oropouche com base na\% de viabilidade celular e no coeficiente de variação. MOI de 1.0 foi escolhido.

4.2.3 Reprodutibilidade do ensaio

Após os parâmetros biológicos do ensaio terem sido definidos, a reprodutibilidade do screening primário para ambos os modelos foi medida quando se avaliaram as curvas dose-resposta do composto Interferon $\alpha 2 \mathrm{~A}$ de três experimentos independentes, seguindo 
o protocolo do ensaio primário. O valor médio de EC50 obtido para o ensaio realizado com Oropouche foi de $20,64 \mathrm{pM}( \pm 2,12)$ e o perfil coincidente das curvas confirmou a consistência do ensaio. A mesma consistência foi obtida no ensaio realizado para Mayaro e o valor médio de EC50 foi de 61,13 pM ( $\pm 15,03)$. Outros compostos de referência citados na literatura foram testados, tais como T705, ácido micofenólico, Bafilomicina e cloroquina. Todos os compostos mostraram atividade, mas eram muito citotóxicos e assim foram descartados como compostos de referência para o ensaio (dados não mostrados).

Foram medidos os valores de Signal to Noise $(9,2 \pm 1,8)$ - onde o valor ideal encontra-se $>3$; e Signal to background $(19,8 \pm 0,9)$ - onde o valor ideal encontra-se $>10$ - para ambos os ensaios em conjunto com o valor de Z $(0,78 \pm 0,06)$ e Coeficiente de variação $(=7,8)$.

Tabela 1. Conclusões de parâmetros do desenvolvimento do ensaio para o vírus Mayaro

\begin{tabular}{|c|c|c|c|}
\hline Parâmetro & Escolha & Testados & Conclusōes \\
\hline Células & Vero & Vero & 5000 cells \\
\hline Veiculo & DMSO & DMSO & $0.2 \%$ DMSO \\
\hline Cepa Viral & BeArs05411 & $\begin{array}{c}\text { BeAr505411;BeAn343102; Uruma; } \\
\text { TRVL4675; Guryanc }\end{array}$ & BeAr505411 \\
\hline Virus MOI & 2.5 & $0.1 ; 0.5 ; 1.0 ; 1.5 ; 2.0 ; 2.5 ; 5.0$ & 2.5 \\
\hline Tempo para leitura & 2. DPL,3 DPI & 2. DPL, 3 DPI & 3 DPI \\
\hline Reagente para leitura & MTT, CTG & MTT, CTG & CTG \\
\hline Dioga controle & T705 & Ribavirin, MPA, T-705, lnterferon & Interferon \\
\hline
\end{tabular}

Tabela 2. Conclusões de parâmetros do desenvolvimento do ensaio para o vírus Oropouche.

\begin{tabular}{|c|c|c|c|}
\hline Parámetro & Escolha & Testados & Conclusōes \\
\hline Células & Vero & Vero & 4500 cells \\
\hline Veiculo & DMSO & DMSO & $0.2 \%$ DMSO \\
\hline Cepa Viral & BeAn 19991 & BeAn19991 & BeAn19991 \\
\hline Virus MOI & 1.0 & $0.1 ; 0.5 ; 1.0 ; 1.5 ; 2.0 ; 2.5 ; 5.0$ & 1.0 \\
\hline Tempo para leitura & 2. DPL, 3 DPI & 2 DPL, 3 DPI & 3 DPI \\
\hline Reagente para leitura & MTT, CTG & MTT, CTG & CTG \\
\hline Droga controle & Interferon & Ribivirin, MPA, T-705 & Interferon \\
\hline
\end{tabular}


4.3 Triagem das Bibliotecas e validação dos ensaios

Foram triados no total 2621 compostos entre as quatro bibliotecas. Os compostos da biblioteca da Universidade de Wisconsin, Pathogen Box e Prestwick Library foram todos examinados em duplicatas independentes seguindo o protocolo validado do ensaio primário para os vírus Mayaro e Oropouche, e todas as placas foram consideradas aprovadas de acordo com o critério de qualidade $(Z \geq 0,5)$; o fator médio $Z$ 'obtido para todas as placas de todas as repetições foi de 0,75 $\pm 0,04$ (Figura 9 e 10). Nenhuma das amostras foi escolhida como positiva, uma vez que nenhuma delas apresentou atividade superior a 50\%. A inibição da infecção causada por estas amostras foi verificada por leitura de luminescência de CTG com Envision (dados não mostrados). A seleção de amostras dessa triagem resultou em uma taxa de acerto de $0 \%$.

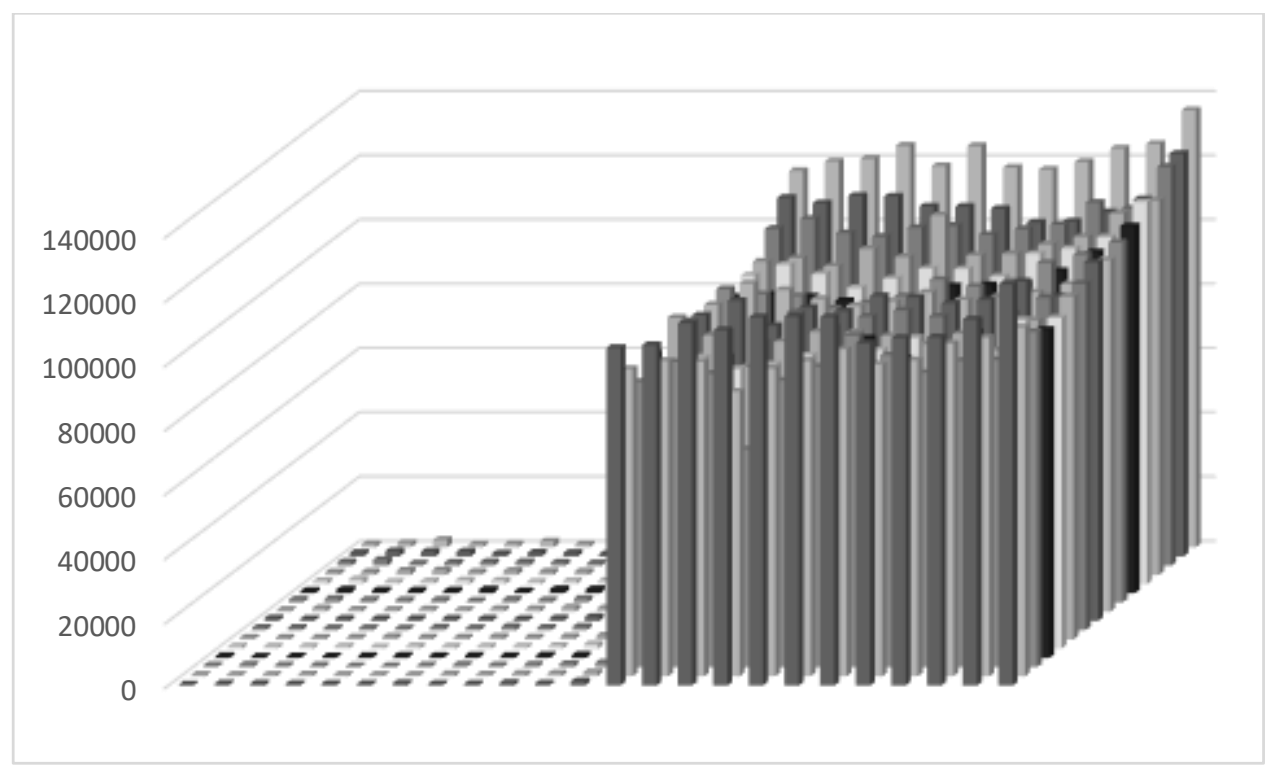

Figura 9. Distribuição gráfica de uma placa Z para o vírus Mayaro. 


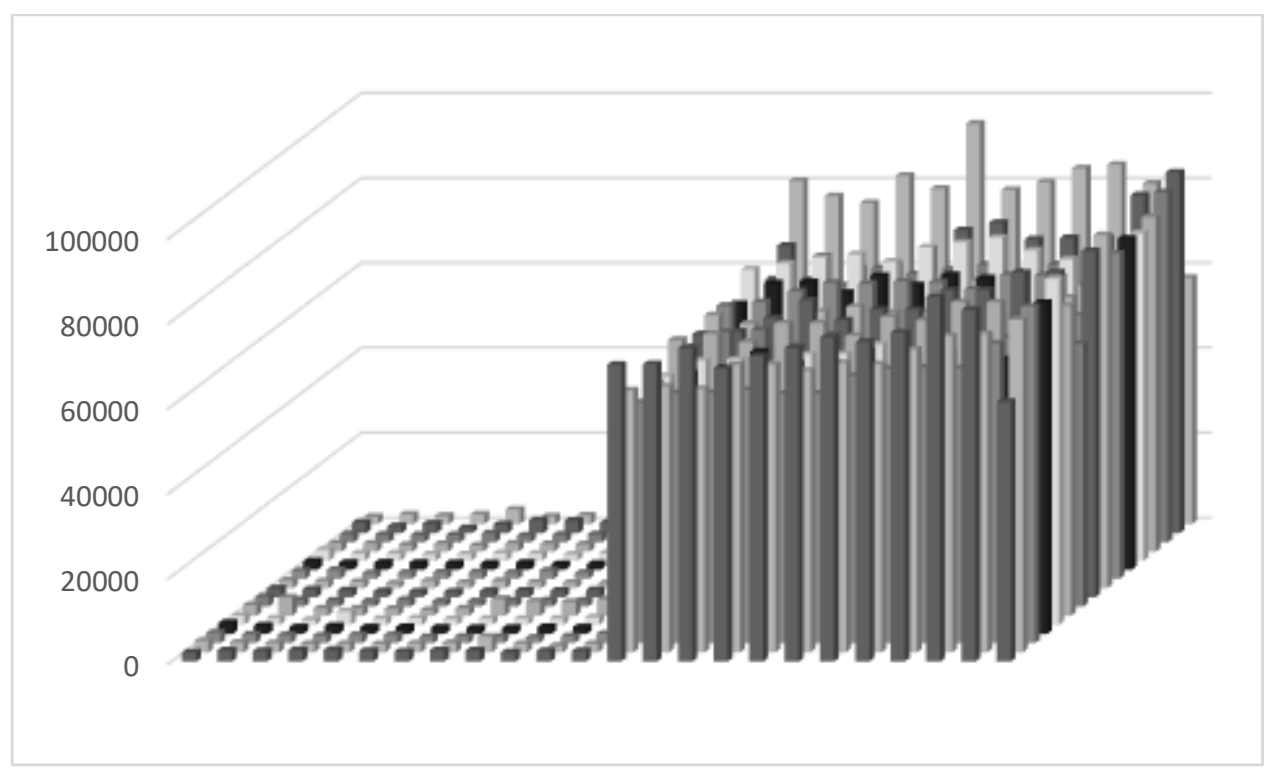

Figura 10. Distribuição gráfica de uma placa Z para o vírus Oropouche.

O screening dos compostos da biblioteca da Purdue University foi feito em triplicatas independentes seguindo o protocolo validado do ensaio primário para Mayaro e Oropouche, e todas as placas foram consideradas aprovadas de acordo com o critério de qualidade $\left(Z^{\geq} \geq 0,5\right)$; o fator médio $Z$ 'obtido para todas as placas de todas as repetições foi de 0,78 $\pm 0,06$. Com base no screening, de todas as 25 amostras, apenas 3 pareciam ser tóxicas para a célula hospedeira, exibindo toxicidade superior a $50 \%$ à concentração testada. Os hits foram selecionados como as 5 amostras mais ativas, com atividade normalizada maior que $50 \%$ e toxicidade celular igual ou menor que 50\%. Foram escolhidas amostras que foram positivas para o critério em ambas as três repetições (5 hits). A inibição da infecção causada por estas amostras foi verificada por leitura de luminescência de CTG com Envision. A seleção de amostras dessa triagem resultou em uma taxa de acerto de $25 \%$. Esses acertos foram selecionados para teste dose-resposta (triagem confirmatória) (Figuras 11 e 12). 

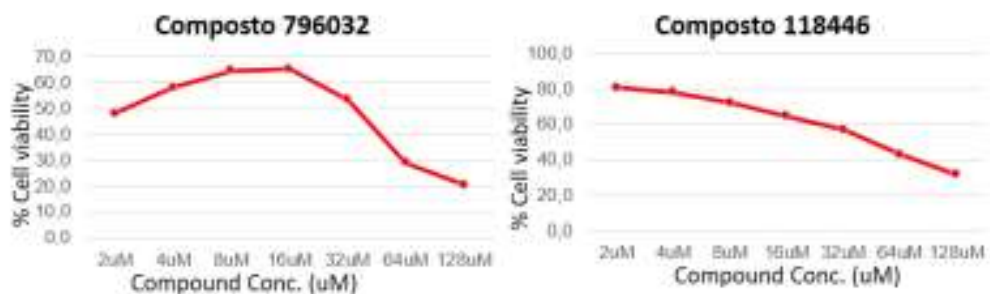

Composto 118550
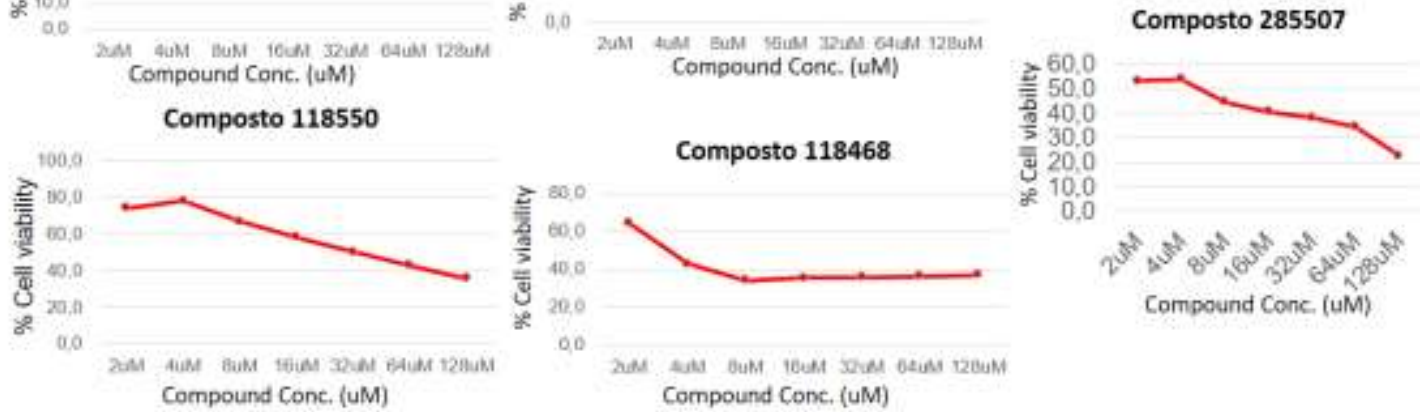

Figura 11. Curva de dose-resposta da Purdue Library com os hits encontrados para o vírus Mayaro.
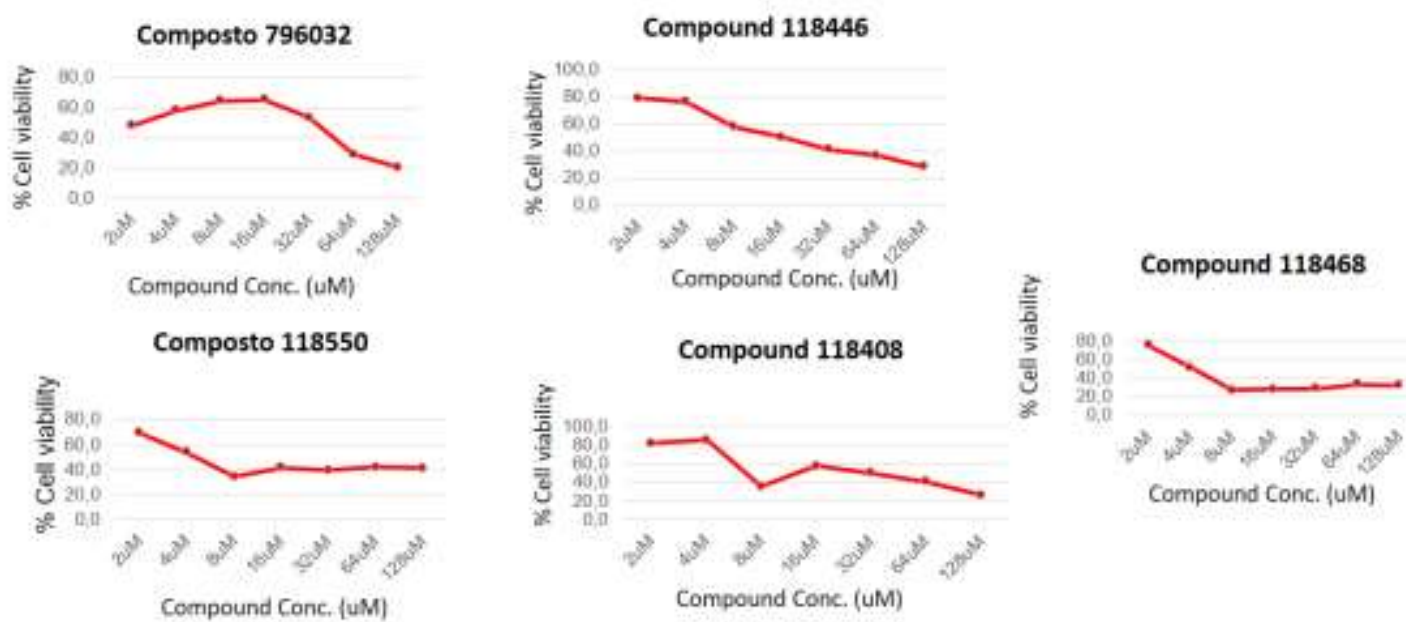

Figura 12. Curvas de dose-resposta para os hits da Purdue Library para o vírus Oropouche

Os hits confirmados mais potentes e eficazes foram as amostras 118550 e 118408 , que exibiram uma atividade próxima de 90\%, com um valor de EC50 relativamente baixo. 
4.4 Ensaio de redução de plaque

No ensaio de redução de plaque para o vírus Mayaro, os compostos 796032, 118550, 118446 e 118468 apresentaram redução visível na formação de plaques quando comparados com o controle de vírus Mayaro. Já os demais compostos apresentaram citotoxicidade quando nesta concentração e neste ensaio, não se mostrando bons candidatos.

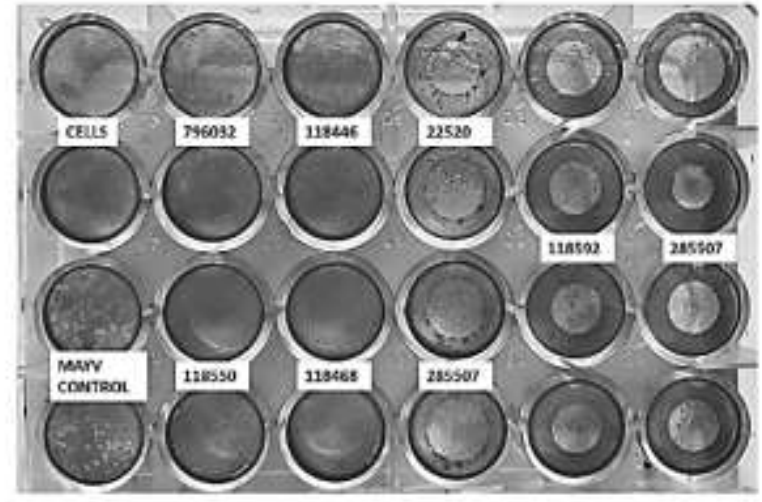

Figura 13. Ensaio de redução de plaque para o vírus Mayaro

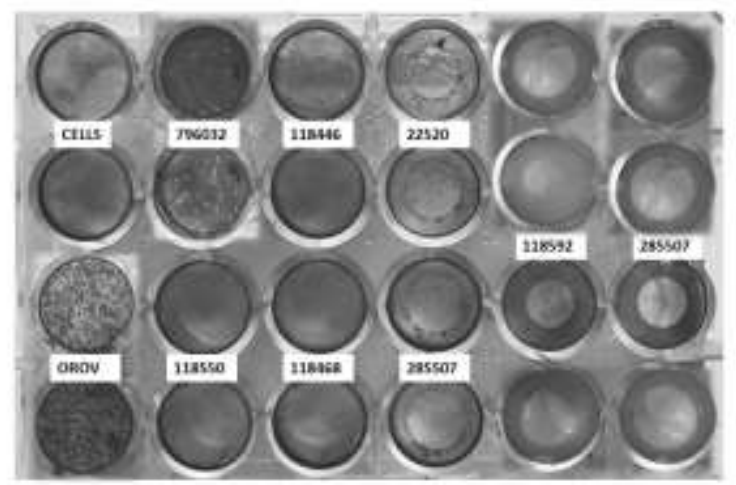

Figura 14. Ensaio de redução de plaque para o vírus Oropouche 
4.5 Ensaio de tempo de adição de droga para Mayaro e Oropouche

O ensaio de tempo de adição (ToA) tem como objetivo determinar por quanto tempo a adição de um determinado composto pode ser adiada antes de perder sua atividade antiviral. Além disso, com esse ensaio podemos avaliar as alterações induzidas pelos compostos na cinética de replicação do vírus, podendo assim determinar em qual estágio do ciclo de vida do vírus determinado composto atua (DAELEMANS et al. 2011). Então, com esse objetivo, os compostos hits escolhidos foram adicionados em vários momentos, antes, durante ou depois da infecção, e os sobrenadantes foram recolhidos após $48 \mathrm{~h}$ de incubação para realizar teste de viabilidade celular com CTG.

Os valores de porcentagem de viabilidade celular X tempo de adição da droga foram utilizados para plotar os gráficos da Figura 15, que mostra os valores para cada um dos compostos para MAYV e OROV. Para o composto 118468, o ensaio apresentou um valor alto de viabilidade celular (91,2\%) -1h e 0h (Figura 15). Esses resultados sugerem que todos os compostos selecionados inibem a infecção nos estágios iniciais da infecção viral, um processo de várias etapas que inclui a ligação do vírus com o receptor da célula hospedeira até a internalização da partícula viral.
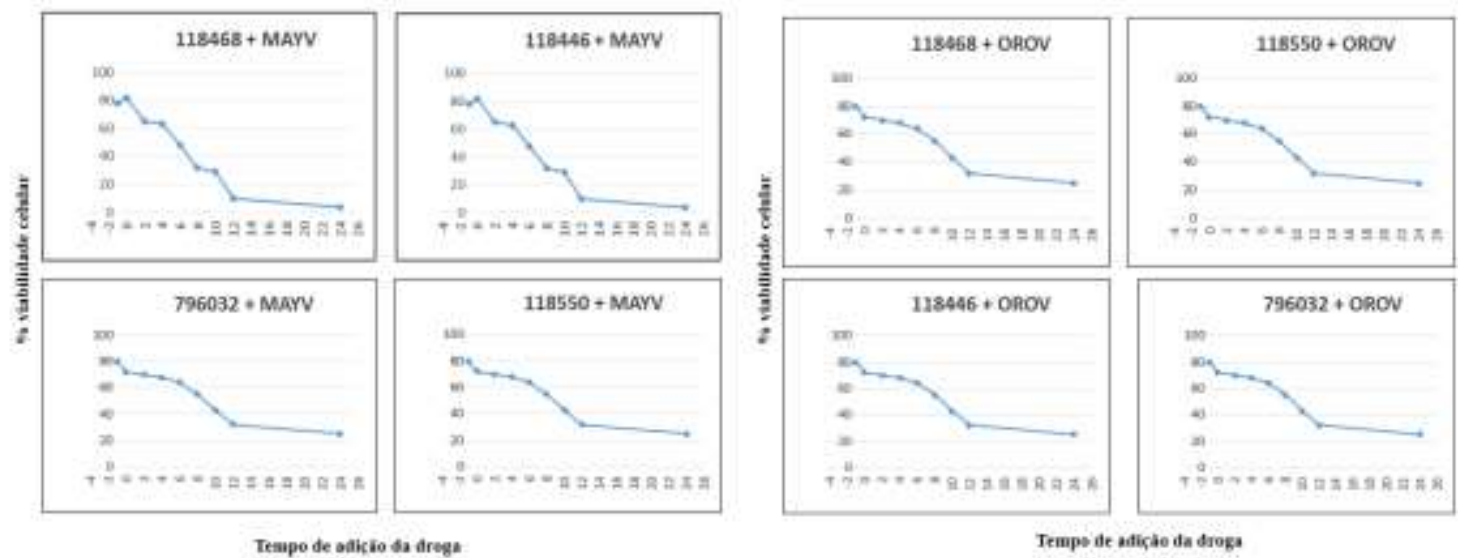

Figura 15. Ensaio de Tempo de adição para MAYV e OROV

Como a diminuição do título viral no ensaio do ToA não foi expressiva no tempo de zero hora, decidimos realizar o ensaio de ligação para confirmar o momento de atuação dos compostos. O período de incubação à $4^{\circ} \mathrm{C}$ permite apenas a ligação do vírus com o receptor, porém as partículas não são internalizadas (Mingorance et al. 2014; Cheng et al. 2015). A etapa de lavagem garante a remoção de vírus não ligados aos receptores, e por 
fim, a troca de temperatura para $37^{\circ} \mathrm{C}$ permite que os vírus ligados sejam internalizados. Com isso, concluímos que os compostos atuam em eventos pós-ligação, ou seja, durante a internalização do vírus, e o composto $X$ atua durante a adsorção viral, provavelmente inibindo a ligação com o receptor.

4.6 Ensaio de espectro de ação de antivirais para os compostos

Com o intuito de verificar o espectro de atividade dos compostos dentro dos gêneros Alphavirus e Orthobunyavirus, ensaios de dose-resposta foram realizados. De acordo com os resultados encontrados os compostos 796032, 118550, 118446 e 118468 apresentaram atividade moderada relacionada a outros Alphavirus mas demonstraram atividade considerável em relação a outros Orthobunyavirus (Tabela 4). 
Tabela 4. Comparação dos valores de EC50, CC50 e índice de seletividade de cada composto selecionado.

\begin{tabular}{|c|c|c|c|c|}
\hline Composto & Vírus & $\mathrm{EC}_{50}(\mu \mathrm{M})$ & $\mathrm{CC}_{50}(\mu \mathrm{M})$ & SI \\
\hline \multirow[t]{8}{*}{796032} & OROV & $0,8 \pm 0,2$ & \multirow{8}{*}{82,8} & $37,5 \pm 1,6$ \\
\hline & Tacaiúma & $6,2 \pm 1,9$ & & $5,1 \pm 0,9$ \\
\hline & Caraparu & $7,4 \pm 2,3$ & & $4,05 \pm 1,2$ \\
\hline & MAYV & $1,2 \pm 0,6$ & & $25,1 \pm 0,8$ \\
\hline & CHIKV & $22,8 \pm 2,34$ & & $1,3 \pm 0,9$ \\
\hline & VEEV & $34,1 \pm 2,9$ & & $0,8 \pm 0,4$ \\
\hline & EEEV & $48,4 \pm 9,8$ & & $0,6 \pm 0,91$ \\
\hline & WEEV & $39,3 \pm 7,3$ & & $0,76 \pm 0,23$ \\
\hline \multirow[t]{8}{*}{118550} & OROV & $1,1 \pm 0,6$ & \multirow{8}{*}{91,4} & $27,2 \pm 1,9$ \\
\hline & Tacaiúma & $6,9 \pm 0,8$ & & $4,35 \pm 0,2$ \\
\hline & Caraparu & $9,5 \pm 1,8$ & & $3,15 \pm 2,4$ \\
\hline & MAYV & $0,9 \pm 0,9$ & & $33,3 \pm 4,9$ \\
\hline & CHIKV & $31,8 \pm 2,9$ & & $0,94 \pm 1,28$ \\
\hline & VEEV & $44,3 \pm 4,3$ & & $0,68 \pm 1,24$ \\
\hline & EEEV & $51,7 \pm 8,8$ & & $0,58 \pm 9,8$ \\
\hline & WEEV & $64,3 \pm 5,9$ & & $0,46 \pm 2,4$ \\
\hline \multirow[t]{8}{*}{118446} & OROV & $0,9 \pm 0,9$ & \multirow{8}{*}{78,3} & $34,1 \pm 0,2$ \\
\hline & Tacaiúma & $8,9 \pm 2,1$ & & $3,38 \pm 2,9$ \\
\hline & Caraparu & $10,2 \pm 3,4$ & & $2,96 \pm 1,8$ \\
\hline & MAYV & $4,8 \pm 0,8$ & & $6,12 \pm 4,2$ \\
\hline & CHIKV & $42,4 \pm 12,9$ & & $0,71 \pm 3,1$ \\
\hline & VEEV & $84,8 \pm 24,1$ & & $0,35 \pm 2,4$ \\
\hline & EEEV & $121,9 \pm 48,8$ & & $0,24 \pm 1,8$ \\
\hline & WEEV & $99,7 \pm 28,8$ & & $0,29 \pm 1,9$ \\
\hline \multirow[t]{8}{*}{118468} & OROV & $2,7 \pm 0,3$ & \multirow{8}{*}{102,1} & $11,2 \pm 2,4$ \\
\hline & Tacaiúma & $8,8 \pm 2,7$ & & $3,4 \pm 1,9$ \\
\hline & Caraparu & $11,4 \pm 3,8$ & & $2,6 \pm 2,4$ \\
\hline & MAYV & $6,2 \pm 0,7$ & & $4,92 \pm 1,8$ \\
\hline & CHIKV & $63,7 \pm 14,5$ & & $0,48 \pm 1,7$ \\
\hline & VEEV & $28,5 \pm 13,4$ & & $1,05 \pm 0.98$ \\
\hline & EEEV & $42,8 \pm 23,3$ & & $0,7 \pm 0.6$ \\
\hline & WEEV & $51,8 \pm 18,6$ & & $0,57 \pm 0,49$ \\
\hline
\end{tabular}




\section{DISCUSSÃO}

O Brasil possui enorme diversidade de fauna e flora, abrigando condições ideais para a manutenção de arboviroses. Com o crescimento das cidades, ciclos silvestres destes vírus vêm se aproximando das áreas urbanas e isto, combinado à facilidade atual de locomoção, permitem o surgimento e a disseminação de doenças (FIGUEIREDO, 2000;2007).

Vários estudos anteriores descrevem a utilização de substancias sintéticas ou naturais como potenciais agentes antivirais em ensaios in vivo e in vitro (PACCA, 2009; TALARICO, 2005; ZHANG, 2009). Entretanto, atualmente não existem fármacos disponíveis no mercado para tratamento contra Alphavirus ou Orthobunyavirus, especialmente MAYV e OROV. Sendo assim, a busca por antivirais torna-se de suma importância, uma vez que infecções por esse vírus são comuns e causam complicações como doença articular ou encefalite.

Até o momento pouco se sabe sobre as proteínas não estruturais de Alphavirus e seu possível papel como alvos de novas moléculas terapêuticas (FARHANA, 2018). O domínio nsP2 abriu caminhos para o desenvolvimento de inibidores específicos em Alphavirus - é de longe, o mais bem definido dos outros domínios da nsP e suas informações estruturais foram inspiradoras para biólogos e químicos ao projetar muitas séries de compostos, visando principalmente a sua atividade catalítica (HU, 2016) Contudo, a falta de informação estrutural sobre os outros nsPs virais torna a compreensão do modo de ação dos inibidores e o planejamento racional de processos específicos e eficientes para a criação de possível inibidores para outros sítios desafiadores. Vale a pena notar que, para todos os inibidores de nsP1 e nsP4, as interações diretas com seus resíduos direcionados nunca foram demonstradas. Em particular, a obtenção da estrutura cristalina do alfhavírus nsP4 RdRp permitiria uma comparação mais robusta dessa polimerase para outros RdRps virais (FARHANA, 2018).

$\mathrm{Na}$ última década, e particularmente desde que o virus Chikungunya chegou às Américas, esforços significativos foram feitos para identificar compostos que inibem efetivamente a replicação do CHIKV. Infelizmente, esses esforços não levaram a um candidato clínico. Nos próximos anos, são necessárias pesquisas mais básicas para permitir uma melhor compreensão da interação das proteínas virais entre elas e com os 
componentes celulares. Faltam informações estruturais para a maioria dos alvos, de modo que o design de medicamentos com base na estrutura, uma estratégia que proporcionou bons resultados em outros campos antivirais, dificilmente foi aplicado aos alfavírus (PÉREZ-PÉREZ, 2019).

Com a ausência de ferramentas para procurar por possíveis candidatos a antivirais para MAYV, Xiaodan et al construíram clones infecciosos da cepa BeAr 20290 do MAYV com uso de eGFP. O vírus repórter exibia alta capacidade de replicação indistinguível do tipo selvagem MAYV e era geneticamente estável em pelo menos cinco rodadas de passagens na célula BHK-21. A expressão de eGFP também mostrou boa correlacão com a replicação viral.

Existe uma preocupação crescente de que OROV, que é endêmico no norte do Brasil, possa se espalhar por todo o país por ciclos urbanos contíguos e através do deslocamento de pessoas. Médicos que trabalham em todo o mundo em áreas para as quais OROV não é endêmico deveriam incluir este virus negligenciado no diagnóstico diferencial da síndrome febril aguda, principalmente em pacientes que visitam áreas de alto risco de transmissão de OROV (VERNAL, 2019).

Para obter um agente terapêutico para prevenir e/ou tratar infecções por Orthobunyavirus, a ação antiviral do interferon-alfa (IFN-alfa) foi avaliada e os resultados in vitro mostraram que todos os os virus estudados eram suscetíveis à ação antiviral do IFN-alfa, mas essa suscetibilidade é limitada e depende da concentração da droga e do período de tratamento (LIVONESI, 2007), corroborando com nossos resultados a respeito. Resultados in vivo demonstraram que o IFN-alfa apresenta ação antiviral nos vírus Oropouche e Guaroa quando usado como tratamento profilático. Além disso, um tratamento iniciado 3 h após a infecção impediu a morte de camundongos infectados pelo vírus Guaroa. A mortalidade de camundongos estava relacionada à migração e replicação de vírus em seus cérebros.

Ácido micofenólico (MPA), um conhecido agente antiviral foi testado para Orthobunyavírus e os resultados demonstraram que o MPA a uma concentração de 10 $\mu \mathrm{g} / \mathrm{ml}$ possui atividade antiviral significativa para o vírus Tacaiuma quando o tratamento foi iniciado 24 horas antes ou 2 horas após a infecção viral, porém o mesmo não se mostrou viável para o virus Oropouche, não havendo inibição da replicação de OROV na presença de MPA. Além disso, o MPA tem um efeito inibitório na replicação do vírus Guama, mas apenas quando o tratamento foi iniciado antes da infecção celular. A adição de guanosina na cultura reverteu o efeito inibitório do MPA nos vírus Tacaiuma e Guama, 
sugerindo que a atividade antiviral dessa substância era por depleção do pool intracelular de guanosine (LIVONESI, 2007).

Outros estudos sugerem que a Ribavirina não possui atividade antiviral nos vírus Oropouche, Caraparu, Guama, Guaroa ou Tacaiuma; consequentemente, a ribavirina não seria um bom agente terapêutico para o tratamento desses arbovirus (LIVONESI, 2006).

Neste estudo, desenvolvemos ensaios de High Throughput Screening (HTS) rápidos, robustos e confiáveis para candidatos a drogas antivirais dos vírus Mayaro e Oropouche. $\mathrm{O}$ desenho dos ensaios foi avaliado por alta sensibilidade, baixo background e alto nível de reprodutibilidade e identificou, em um primeiro momento, cinco compostos promissores para cada um dos vírus. As cepas dos vírus e a linhagem celular foram críticas para a precisão e reprodutibilidade dos ensaios.

As células Vero são conhecidas por serem uma ótima linhagem celular para os Alphavirus (REFERÊNCIA AQUI) e a cepa de MAYV BeAr 20290, que foi isolada dos mosquitos Haemagogus em 1960 no Brasil (Esposito e da Fonseca, 2015). Em um formato de 384 poços, as células Vero (ATCC CCL81) têm uma taxa de crescimento reduzida no meio de ensaio (tempo de duplicação de $\sim 48 \mathrm{~h}$ ), o que pode contribuir para a estabilidade do ensaio, diminuindo os artefatos induzidos pela rápida metabolização das células. O ensaio abrange a entrada viral, síntese de RNA e saída viral da célula hospedeira, uma vez que as células são expostas ao MAYV por $72 \mathrm{~h}$, respeitando a biologia viral durante a infecção do hospedeiro. Observamos uma alta tolerância ao DMSO no meio de ensaio e as células sobreviveram em até $2 \%$ de DMSO por $>72 \mathrm{~h}$, com apenas uma redução de duas vezes na CPE induzida por vírus na mesma concentração de DMSO.

A maior contribuição para a sensibilidade e baixo nível de background é o reagente CellTiter Glo (CTG) como uma medida da viabilidade celular. Este método de determinação de efeito citopático tem uma grande vantagem sobre o ensaio de captação de vermelho neutro, pois o protocolo de adição de reagente único é facilmente adaptável ao HTS.

Nos últimos anos, os arbovírus, incluindo WNV, DENV, ZIKV e CHIKV, ressurgiram e causaram vários surtos em todo o mundo (Hotez e Murray, 2017). Figueiredo sugeriu que Alphavirus podem "sofrer mutações e/ou se adaptar a novos ciclos zoonóticos e, assim, adquirir um maior potencial de emergência", causando epidemias significativas. O MAYV está filogeneticamente relacionado ao CHIKV e causa surtos de 
doenças febris com envolvimento articular na região amazônica. O MAYV pode emergir em outras regiões do país se se adaptar à transmissão do Aedes (FIGUEIREDO, 2014).

Os vírus MAYV e OROV causam uma variedade de sintomas comuns entre, e freqüentemente indistinguíveis clinicamente, daqueles causados por infecção por outros arbovírus. Por esse motivo, os casos de MAYV relatados até o momento provavelmente representam apenas a ponta do iceberg. Além disso, os surtos de MAYV podem coocorrer com ou próximo a CHIKV, DENV, YFV ou outros surtos de arbovírus. Provavelmente, isso contribui para o subdiagnóstico devido às semelhanças na apresentação clínica com as doenças mais conhecidas (ANDERSON, 1957).

Para que um antiviral seja considerado eficiente, este deve interferir minimamente na estrutura e metabolismo da célula do hospedeiro, não apresentar toxicidade,e ao mesmo tempo inibir a replicação viral (DE MEYER, 1989). Fatores como a concentração do material teste, tempo de exposição, linhagem célular, entre outros, podem ou não apresentar diferentes intensidades de lesão célular (HU, 1989). Sendo assim, a avaliação da citotoxicidade pelos compostos é de extrema importância, pois, alterações na sobrevivência, multiplicação e metabolização das células utilizadas nos ensaios, causadas pelos compostos, levariam ao descarte dos mesmos, uma vez que não se encaixariam como potentes antivirais (NARDONE, 1977). No presente estudo, a citotoxicidade dos compostos foi baixa quando utilizados na concentração de $10 \mu \mathrm{g} / \mathrm{mL}$, o que possibilitou a continuidade do trabalho.

Assim, os estudos sobre novos antivirais devem continuar, pois a possibilidade de futuras epidemias permanece claramente plausível. Diante disso, destacamos a importância dessa metodologia e sua capacidade de encontrar possíveis novos alvos terapêuticos para os vírus Mayaro e Oropouche. 


\section{CONCLUSÕES}

1. Com o intuito de pesquisar compostos com amplo espectro viral contra Alphavirus e Orthobunyavirus, estabelecemos um ensaio de alto conteúdo para triagem de bibliotecas em células Vero infectadas com vírus vivos. Baseado em ensaios previamente descritos na literatura, foi desenvolvido um protocolo otimizado que se mostrou robusto, sensível e reprodutível, capaz de identificar adequadamente moléculas com potencial atividade antiviral. As condições de ensaio foram otimizadas para obtermos as condições de ensaio ideais.

2. Foram identificadas 4 moléculas com atividade antiviral satisfatória para ambos os vírus, validando a nossa abordagem como uma tecnologia viável para a descoberta de antivirais.

3. Ensaios de tempo de adição de droga mostraram que estes compostos atuam nos momentos iniciais da infecção viral.

4. Os compostos também foram caracterizados quanto a sua atividade contra outros vírus do mesmo gênero. Os resultados mostraram um perfil de atividade variado para os compostos testados. Estes testes realizados com o painel de vírus são importantes para uma melhor caracterização do potencial de atividade dos compostos, permitindo assim uma seleção mais refinada de compostos de amplo espectro viral.

5. Em suma, a metodologia descrita nesse trabalho representa uma importante contribuição para os processos iniciais de desenvolvimento de antivirais. 


\section{REFERÊNCIAS}

1. ACRANI GO, GOMES R, PROENÇA-MÓDENA JL, DA SILVA AF, CARMINATI PO, SILVA ML, SANTOS RI, ARRUDA E. Apoptosis induced by Oropouche vírus infection in HeLa cells is dependente on vírus protein expression. Virus Res. 2010, 149:56-63.

2. ADCOCK, ROBERT S., YONG KYU CHU, JENNIFER E. GOLDEN, AND DONG HOON CHUNG. 2017. "Evaluation of Anti-Zika Virus Activities of Broad-Spectrum Antivirals and NIH Clinical Collection Compounds Using a Cell-Based, High-Throughput Screen Assay.” Antiviral Research 138. Elsevier B.V.: 47-56. doi:10.1016/j.antiviral.2016.11.018.

3. AHOLA, T. AND L. KAARIAINEN, Reaction in alphavirus mRNA capping: formation of a covalent complex of nonstructural protein nsP1 with 7-methylGMP. Proc Natl Acad Sci U S A, 1995. 92(2): p. 507-11.

4. ANDERSON CR, SPENCE L, DOWNS WG, AITKEN TH. Oropouche virus: a new human disease agent from Trinidad, West Indies. Am J Trop Med Hyg, 1961, 10:574-578.

5. ANDERSON, C.R., et al., Mayaro virus: a new human disease agent. II. Isolation from blood of patients in Trinidad, B.W.I. Am J Trop Med Hyg, 1957. 6(6): p. 1012-6.

6. AZEVEDO, RS; NUNES, MR; CHIANG, JO; BENSABATH, G; VASCONCELOS, HB; PINTO, AY; MARTINS, LC; MONTEIRO, HA; RODRIGUES, SG e VASCONCELOS, PF. Reemergence of Oropouche fever, northern Brazil. Emerg Infect Dis, 2007, 13(6):912-915.

7. BO ZHANG, AND HAN QING YE. 2018. "Development of a Replicon Cell Line-Based High Throughput Antiviral Assay for Screening Inhibitors of Zika Virus." Antiviral

8. BOGGS, W.M., et al., Low pH-dependent Sindbis virus-induced fusion of BHK cells: differences between strains correlate with amino acid changes in the E1 glycoprotein. Virology, 1989. 169(2): p. 485-8.

9. CABARCAS-MONTALVO, MARIA, WILSON MALDONADO-ROJAS, DIANA MONTES-GRAJALES, ANGELA BERTEL-SEVILLA, IRENE WAGNER-DÖBLER, HELENA SZTAJER, MICHAEL RECK, MARIA FLECHAS-ALARCON, RAQUEL OCAZIONEZ, AND JESUS OLIVERO- 
VERBEL. 2016. "Discovery of Antiviral Molecules for Dengue: In Silico Search and Biological Evaluation.” European Journal of Medicinal Chemistry 110: 8797.doi:10.1016/j.ejmech.2015.12.030.

10. CHAMBERLAIN, R., Epidemiology of arthropod-borne togaviruses: the role of arthropods as hosts and vectors and of vertebrate hosts in natural transmission cycles. Academic Press, 1980: p. 175 - 227.

11. DUPUIS-MAGUIRAGA, L., et al., Chikungunya disease: infection-associated markers from the acute to the chronic phase of arbovirus-induced arthralgia. PLoS Negl Trop Dis, 2012. 6(3): p. e1446.

12. ELLIOTT, RM; SCHMALJOHN, CS. Bunyaviridae. Fields Virology, Sixth Edition. LIPPINCOTT WILLIAMS \& WILKINS, Philadelphia, 2013, 1(42):1244-1282.

13. GANE, EDWARD J, CATHERINE A STEDMAN, ROBERT H HYLAND, D PHIL, XIAO DING, EVGUENIA SVAROVSKAIA, WILLIAM T SYMONDS, ROBERT G HINDES, AND M MICHELLE BERREY. 2013. "Nucleotide Polymerase Inhibitor Sofosbuvir plus Ribavirin for Hepatitis C." The New England Journal of Medicine 368 (1): 34-44. doi:10.1056/NEJMoa1208953.

14. GOMEZ DE CEDRON, M., et al., RNA helicase activity of Semliki Forest virus replicase protein NSP2. FEBS Lett, 1999. 448(1): p. 19-22.

15. GREEN, NEIL, ROBERT D OTT, RICHARD J ISAACS, AND HONG FANG. 2008. “Cell-Based Assays to Identify Inhibitors of Viral Disease.” Expert Opinion on Drug Discovery 3 (6): 671-76. doi:10.1517/17460441.3.6.671.

16. GUU, TSY; ZHENG, W; TAO, YJ. Bunyavirus: Structure and replication. Adv Exp Med Biol, 2012, 726:245-266.

17. HAHN, Y.S., et al., Mapping of RNA-temperature-sensitive mutants of Sindbis virus: complementation group F mutants have lesions in nsP4. J Virol, 1989. 63(3): p. 1194-202.

18. HARDY, W.R. AND J.H. STRAUSS, Processing the nonstructural polyproteins of sindbis virus: nonstructural proteinase is in the C-terminal half of nsP2 and functions both in cis and in trans. J Virol, 1989. 63(11): p. 4653-64.

19. HELENIUS, A., et al., On the entry of Semliki forest virus into BHK-21 cells. J Cell Biol, 1980. 84(2): p. 404-20.

20. HENDERSON, BRITTNEY R, BEJAN J SAEEDI, AND SUSAN M KEENAN. 2012. “A High- Throughput Screening Assay for the Identification of Flavivirus 
NS5 Capping Enzyme GTP-Binding Inhibitors: Implications for Antiviral Drug Development." Journal of Biomolecular Screening 16 (8): 852-61. doi:10.1177/1087057111412183.A.

21. HERMANN, LAURA L., SWATI B. GUPTA, SUSAN B. MANOFF, SIRIPEN KALAYANAROOJ, ROBERT V. GIBBONS, AND BETH-ANN G. COLLER. 2015. "Advances in the Understanding, Management, and Prevention of Dengue." Journal of Clinical Virology 64: 153-59. Pastorino, Boris, Antoine Nougairède, Nathalie Wurtz, Ernest Gould, and Xavier De Lamballerie. 2010. "Role of Host Cell Factors in Flavivirus Infection: Implications for Pathogenesis and Development of Antiviral Drugs." Antiviral Research 87: 281-94. doi:10.1016/j.antiviral.2010.04.014.

22. IVANOVA, L., L. LE, AND M.J. SCHLESINGER, Characterization of revertants of a Sindbis virus $6 K$ gene mutant that affects proteolytic processing and virus assembly. Virus Res, 1995. 39(2-3): p. 165-79.

23. KOUZNETSOVA, JENNIFER, WEI SUN, CARLES MARTÍNEZ-ROMERO, GREGORY TAWA, PAUL SHINN, CATHERINE Z CHEN, AARON SCHIMMER, et al. 2014. "Identification of 53 Compounds That Block Ebola Virus-like Particle Entry via a Repurposing Screen of Approved Drugs." Emerging Microbes and Infections 3 (e84): 1-7. doi:10.1038/emi.2014.88.

24. KUMAR, KULDEEP, PANKAJ KUMAR SINGH, JUHI TOMAR, AND SWATI BAIJAL. 2010. "Dengue: Epidemiology, Prevention and Pressing Need for Vaccine Development.” Asian Pacific Journal of Tropical Medicine 3 (12). Hainan Medical College: 997-1000. doi:10.1016/S1995-7645(11)60017-5.

25. LEDUC, JW; PINHEIRO, FP. Oropouche fever. In: Monath, TP (Ed). The arboviruses: Epidemiology and Ecology. Vol 4:1-14, CRC Press, Boca Raton, 1989.

26. LEMM, J.A., et al., Polypeptide requirements for assembly of functional Sindbis virus replication complexes: a model for the temporal regulation of minus-and plus-strand RNA synthesis. EMBO J, 1994. 13(12): p. 2925-34.

27. LI, JIA QI, CHENG LIN DENG, DAYONG GU, XIAO LI, LEI SHI, JIAN'AN HE, QIU YAN ZHANG, LOW, JENNY G.H., ENG EONG OOI, AND SUBHASH G. VASUDEVAN. 2017. "Current Status of Dengue Therapeutics Research and Development." The Journal of Infectious Diseases 215 (2): S96102. doi:10.1093/infdis/jiw423. Abushouk, Abdelrahman Ibrahim, Ahmed 
Negida, and Hussien Ahmed. 2016. "Na Updated Review of Zika Virus.” Journal of Clinical Virology 84. Elsevier B.V.: 53- 58. doi:10.1016/j.jcv.2016.09.012.

28. LUCAS-HOURANI, MARIANNE, DANIEL DAUZONNE, PIERRE JORDA, GAË LLE COUSIN, ALEXANDRU LUPAN, OLIVIER HELYNCK, GRÉ GORY CAIGNARD, et al. 2013. "Inhibition of Pyrimidine Biosynthesis Pathway Suppresses Viral Growth through Innate Immunity.” PLoS Pathogens 9 (10): 118. doi:10.1371/journal.ppat.1003678.

29. LUNA, LKS; RODRIGUES, AH; SANTOS, RI; SESTI-COSTA, R; CRIADO, MF; MARTINS, RB; SILVA, ML; DELCARO, LS; PROENÇA-MODENA, JL; FIGUEIREDO, LT; ACRANI, GO; ARRUDA, E. Oropouche virus is detected in peripheral blood leukocytes from patients. Journal of Medical Virology, 2017 Jun; 89(6):1108-1111.

30. MALET, H., et al., The crystal structures of Chikungunya and Venezuelan equine encephalitis virus nsP3 macro domains define a conserved adenosine binding pocket. J Virol, 2009. 83(13): p. 6534-45.

31. MARTINEZ, J. P., F. SASSE, M. BRÖNSTRUP, J. DIEZ, AND A. MEYERHANS. 2015. “Antiviral Drug Discovery: Broad-Spectrum Drugs from Nature.” Natural Products Reports 32 (1): 29-48. doi:10.1039/C4NP00085D.

32. MIRZA, SHAHER BANO, RAMIN EKHTEIARI SALMAS, M. QAISER FATMI, AND SERDAR DURDAGI. 2016. "Virtual Screening of Eighteen Million Compounds against Dengue Virus: Combined Molecular Docking and Molecular Dynamics Simulations Study.” Journal of Molecular Graphics and Modelling 66. Elsevier Inc.: 99-107. doi:10.1016/j.jmgm.2016.03.008.

33. MORRISON, T.E., et al., A mouse model of chikungunya virus-induced musculoskeletal inflammatory disease: evidence of arthritis, tenosynovitis, myositis, and persistence. Am J Pathol, 2011. 178(1): p. 32-40.

34. MOURAO, M.P., et al., Mayaro fever in the city of Manaus, Brazil, 2007-2008. Vector Borne Zoonotic Dis, 2012. 12(1): p. 42-6.

35. MOURÃO, MP; BASTOS, MS; GIMAQUE, JB; MOTA, BR; SOUZA, GS; GRIMMER, GH; GALUSSO, ES; ARRUDA, E; FIGUEIREDO, LT. Oropouche fever outbreak, Manaus, Brazil, 2007-2008. Emerg Infect Dis. 2009 Dec; 15(12):2063-2064. 
36. NICHOL, S. T. 2001. Bunyaviruses, p. 1603-1633. In B. N. Fields, D. M. Knipe, P. M. Howley, and D. E. Griffin (ed.), Fields virology, 4th ed. Lippincott Williams \& Wilkins, Philadelphia, PA.

37. NUNES, MRT; MARTINS, LC; RODRIGUES, SG; CHIANG, JO; AZEVEDO, RSS; TRAVASSOS DA ROSA, APA; Vasconcelos, PFC. Oropouche virus isolation, southeast Brazil. Emerg Infect Dis, 2005, 11(10):1610-1613.

38. NWAKA, SOLOMON, AND ROBERT G RIDLEY. 2003. "Virtual Drug Discovery and Development for Neglected Diseases through Public-Private Partnerships." Nature Reviews Drug Discovery 2 (11): 919-28. doi:10.1038/nrd1230.

39. OWEN, K.E. AND R.J. KUHN, Identification of a region in the Sindbis virus nucleocapsid protein that is involved in specificity of RNA encapsidation. J Virol, 1996. 70(5): p. 2757-63.

40. PANCHAL, REKHA G., KRISHNA P. KOTA, KEVIN B. SPURGERS, GORDON RUTHEL, JULIE P. TRAN, ROBERT C. BOLTZ, AND SINA BAVARI. 2010. "Development of High-Content Imaging Assays for Lethal Viral Pathogens." Journal of Biomolecular Screening 15 (7): 755-65. doi:Doi $10.1177 / 1087057110374357$.

41. PARK, E. AND D.E. GRIFFIN, The nsP3 macro domain is important for Sindbis virus replication in neurons and neurovirulence in mice. Virology, 2009. 388(2): p. 305-14.

42. PINHEIRO, FP; HOCH, AL; GOMES, ML; ROBERTS, DR. Oropouche vírus. IV. Laboratory transmission by Culicoides paraenses. The Am J of Trop Med and Hyg, 1981, 30(1)172-176.

43. PINHEIRO, FP; PINHEIRO, M; BENSABATH, G; CAUSEY, OR; SHOPE, RE. Epidemia de vírus Oropouche em Belém. Revista do Serviço Especial de Saúde Pública, 1962, 12:15-23.

44. PINHEIRO, FP; TRAVASSOS DA ROSA, AP; TRAVASSOS DA ROSA, JF; ISHAK, R; FREITAS, RB; GOMES, ML; LEDUC, JW; OLIVA, OFP. Oropouche Virus. I. A Review of Clinical, Epidemiological, and Ecological Findings. Am J Trop Med Hyg, 1981, 30:149-60.

45. PINHEIRO, FP; TRAVASSOS DA ROSA, APA; VASCONCELOS, PFC. Oropouche fever. In: Feigin RD, ed Textbook of Pediatric Infectious Diseases, 5th edn. Philadelphia: Saunders; 2004, 2418-2423. 
46. POERSCH, CELINA DE OLIVEIRA, DANIELA PARADA PAVONI, MARIO H. QUEIROZ, LUANA DE BORBA, SAMUEL GOLDENBERG, CLAUDIA NUNES DUARTE DOS SANTOS, AND MARCO AURÉLIO KRIEGER. 2005. "Dengue Virus Infections: Comparison of Methods for Diagnosing the Acute Disease." Journal of Clinical Virology 32: 272-77. doi:10.1016/j.jcv.2004.08.008. Research 150 (December 2017). Elsevier: 14854. doi:10.1016/j.antiviral.2017.12.017. S205-12. doi:10.1086/520601.

47. SAIZ, JUAN-CARLOS, AND MIGUEL A MARTÍN-ACEBES. 2017. "The Race To Find Antivirals for Zika Virus." Antimicrobial Agents and Chemotherapy 61 (6): 1-9. doi:10.1128/AAC.00411-17.

48. SCHMALJOHN, CS; NICHOL, ST. Bunyaviridae. In: Knipe DM et al (Eds), Fields Virology (5th Ed), Lipincott-Williams and Wilkins, Philadelphia, 2006. Vol 2. pp. 1741-1789.

49. SCHWARTZ, O. AND M.L. ALBERT, Biology and pathogenesis of chikungunya virus. Nat Rev Microbiol, 2010. 8(7): p. 491-500.

50. STILES, K.M. AND M. KIELIAN, Alphavirus entry: NRAMP leads the way. Cell Host Microbe, 2011. 10(2): p. 92-3.

51. STRAUSS, J.H. AND E.G. STRAUSS, The alphaviruses: gene expression, replication, and evolution. Microbiol Rev, 1994. 58(3): p. 491-562.

52. TAM, DONG T.H., TRAN V. NGOC, NGUYEN T.H. TIEN, NGUYEN T.T. KIEU, TRUONG T.T. THUY, LAI T.C. THANH, CAO T. TAM, ET AL. 2012. "Effects of Short-Course Oral Corticosteroid Therapy in Early Dengue Infection in Vietnamese Patients: A Randomized, Placebo-Controlled Trial." Clinical Infectious Diseases 55 (9): 1216-24. doi:10.1093/cid/cis655.

53. TESH, R.B., et al., Mayaro virus disease: an emerging mosquito-borne zoonosis in tropical South America. Clin Infect Dis, 1999. 28(1): p. 67-73.

54. TRICOU, VIANNEY, NGUYET NGUYEN MINH, TOI PHAM VAN, SUE J. LEE, JEREMY FARRAR, BRIDGET WILLS, HIEN TINH TRAN, AND CAMERON P. SIMMONS. 2010. "A Randomized Controlled Trial of Chloroquine for the Treatment of Dengue in Vietnamese Adults." PLoS Neglected Tropical Diseases 4 (8). doi:10.1371/journal.pntd.0000785.

55. VEACESLAV, MIRA A. M. BEHNAM, NIKOS VASILAKIS, AND CHRISTIAN D. KLEIN. 2017. "Broad-Spectrum Agents for Flaviviral 
Infections: Dengue, Zika and Beyond." Nature Reviews Drug Discovery 16. Nature Publishing Group: 565-86. doi:10.1038/nrd.2017.33.

56. WEAVER, S.C. AND W.K. REISEN, Present and future arboviral threats. Antiviral Res, 2010. 85(2): p. 328-45. 